\title{
Dynamic Pricing and Investment from Static Proxy Models
}

\author{
DAVID M. MANDY*
}

Department of Economics, University of Missouri

WILLIAM W. SHARKEY

Office of Strategic Planning and Policy Analysis, Federal Communications Commission, Washington, D.C.

\begin{abstract}
This paper evaluates the use of static cost proxy models in setting forward-looking prices such as the prices set according to the FCC's TELRIC methodology. First, it compares the time paths of prices and depreciation under traditional regulatory accounting with the prices and depreciation implied by various versions of TELRIC. When TELRIC prices are recomputed at intervals shorter than asset lives, the firm will generally not earn the target rate of return. In these cases, a correction factor must be applied to the TELRIC price path in order for revenues to exactly recover investment cost, including the target rate of return. Next, the paper considers a firm's cost minimizing investment decisions under two different assumptions about asset obsolescence. In both scenarios, cost minimizing investment paths and implied utilization rates for the firm's assets are derived under a variety of assumptions about the relevant input parameters. Some implications for TELRIC pricing are then derived.
\end{abstract}

\section{Introduction}

In February 1996 the U.S. Congress passed the Telecommunications Act of 1996, which significantly amended the Communications Act of $1934 .{ }^{1}$ The goals of the 1996 Act were, among other things, to open local telecommunications markets to competitive entry and to deregulate where regulation was no longer necessary. ${ }^{2}$ Implementation of the 1996 Act by the Federal Communications Commission (FCC) included development of a new regulatory pricing standard known as "Total Element Long Run Incremental Cost"

\footnotetext{
* Contact author. Mailing address: Department of Economics, University of Missouri, 118 Professional Building, Columbia, MO 65211. Email: MandyD@missouri.edu The authors acknowledge helpful discussions with Jay Atkinson during preparation of this paper. We also benefited from the comments of Simon Wilkie and Donald Stockdale on an earlier draft. The views expressed in this paper, however, are those of the authors alone and do not necessarily reflect the views of the Federal Communications Commission, any Commissioners, or other staff.

${ }^{1}$ Telecommunications Act of 1996, Pub. L. No. 104, 110 Stat. 56 (hereinafter “1996 Act”), 47 U.S.C.

${ }^{2}$ See Joint Managers' Statement, S. Conf. Rep. No. 104-320, 104 ${ }^{\text {th }}$ Cong., 2d Sess. 113 (1996) at 1.
} 
(TELRIC). ${ }^{3}$ TELRIC has been used to price unbundled network elements and interconnection, ${ }^{4}$ and has been widely criticized both as a conceptual framework and as actually applied by regulators. ${ }^{5}$ An underlying current in many of these criticisms is the static nature of TELRIC pricing as implemented to date, when actual telecommunications industry costs are highly dynamic.

This paper considers how TELRIC pricing can be correctly implemented in a dynamic environment. We do this by exploring first, in Section 2, how prices that are periodically reviewed can be calculated to recover the cost of a given investment in physical equipment. Second, Section 3 studies how dynamically efficient investment plans can be calculated, thereby giving the costs to be recovered via the pricing rules discussed in Section 2. Together, Sections 2 and 3 move beyond the criticisms and substantially toward theoretically sound TELRIC pricing rules that can actually be applied in practice. In contrast, the existing literature is long on criticisms of TELRIC but short indeed on suggesting rules and calculations thereof that show how TELRIC prices as currently implemented might be modified to address some of the criticisms. ${ }^{6}$ Our contribution is to take this next step, with particular emphasis on correctly capturing the dynamics of the industry and the sense in which costs and prices should be forward-looking.

One way to view TELRIC is as a new form of incentive regulation. Traditional incentive regulation tries to induce socially efficient behavior from a franchise monopolist. The traditional approach was precluded by the 1996 Act, however, which nullified the state and local statutes that historically granted franchise monopoly status to incumbents, and charged the FCC and state regulators with creating rules under which new competition would operate. ${ }^{7}$ Under the "incentive regulation" view, by adopting TELRIC, the FCC tried to create a market structure in a highly concentrated industry that provides incentives for efficient investment decisions similar to those present in competitive industries with many small suppliers. Under this view, TELRIC tries to induce socially efficient behavior from firms that may have significant market power, thereby sharing the same goal as traditional incentive regulation. But unlike traditional incentive regulation, TELRIC must pursue this goal outside of the franchise monopoly market structure. TELRIC therefore tries to induce efficient investment decisions, including efficient entry and exit, in an industry that, because of high concentration and substantial scale economies, might experience very little (efficient) entry and exit without such inducement. There is substantial disagreement over whether TELRIC succeeds in promoting efficient investment by both entrants and incumbents, or whether it is even possible for price regulation to

\footnotetext{
${ }^{3}$ See Implementation of the Local Competition Provisions of the Telecommunications Act of 1996 (hereinafter Local Competition Order), 11 FCC Rcd 15499, 15509, and 15812-15922 (1996).

${ }^{4}$ The 1996 Act envisioned three alternative methods for competitive entry: Construction of new network facilities, resale of the incumbent firm's retail services, and leasing of unbundled network elements from the incumbent. The 1996 Act also required incumbents to provider interconnection. See 47 U.S.C. $\S \S 251(c)(4)$, 252(d)(3), and 253.

${ }^{5}$ See, for example, Hausman (1997); Kahn (1998, 2001); Sidak and Spulber (1998); Alleman (1999); Kahn, Tardiff, and Weisman (1999); Salinger (1999); Weisman (2000); Mandy (2002); Tardiff (2002); Weisman (2002), and Weingarten and Stuck (2003). Although these studies differ in their points of emphasis, all are critical of at least some aspects of TELRIC in theory or practice.

${ }^{6}$ Exceptions are Hausman (1997), Mandy (2002), Tardiff (2002) and Weingarten and Stuck (2003). However, even these papers do not calculate prices and costs under the variety of possible assumptions considered herein, and only Mandy (2002) presents evidence on dynamic and forward-looking price and cost paths that might form a conceptually sound basis for revisions to TELRIC pricing as currently practiced. 77 U.S.C. $\S 253$.
} 
achieve this objective. ${ }^{8}$ However, even those most critical of the TELRIC methodology agree that the 1996 Act "... asks regulators to create prices that will induce appropriate new entry." "In other words, Congress charged the FCC and state regulators with incentive regulating entry and exit, and doing so via price regulation.

The strong objections of some writers, as well as incumbent local exchange carriers (ILECs), to TELRIC as a methodology and to its specific implementation by state regulatory commissions fall into three categories. First, some have questioned the theoretical consistency of the TELRIC methodology itself. Specifically, ILECs have argued that, when equipment prices are falling over time, periodic recalculation of TELRIC prices prevents them from recovering their investment costs. Second, some have criticized the way state commissions have implemented TELRIC. They argue either that states have adopted unrealistic input values or that the cost models adopted contained flawed model algorithms. ${ }^{10}$ Finally, some have argued that any forward-looking pricing methodology, including TELRIC, in which the computation of cost is not based on the incumbent's "actual network" as a starting point, is inconsistent with the meaning of the 1996 Act.

This paper examines these claims. ${ }^{11}$ Section 2 studies whether TELRIC, as implemented, permits cost recovery of investments in physical equipment. We show that the claim of potential under-recovery is correct. When investment costs are falling over time and TELRIC price reviews are conducted at intervals shorter than expected asset lives, a firm will earn less than its target rate of return under the TELRIC methodology as generally implemented. A TELRIC price is usually computed as a constant (or levelized) price that, over the life of the asset, will earn sufficient revenue to recover the full cost of investment including the target rate of return. This paper shows that when TELRIC prices are recomputed at intervals shorter than these asset lifetimes, and investment costs fall between price reviews, actual revenues will not fully compensate the firm. The paper shows in addition that it is possible to compute a correction factor based on estimates of the rate of change of investment cost and the expected time between TELRIC reviews. Corrected TELRIC prices rise or fall at the same rate over time as underlying investment cost, and allow the firm to earn its target rate of return no matter how frequently price reviews are conducted. Moreover, no ad hoc adjustments of assumed asset lifetimes or depreciation schedules are needed to implement the suggested correction.

Section 3 of the paper partially addresses the second and third objections raised to TELRIC pricing. We consider two stylized assumptions about asset replacement. Under one scenario, which we call "expected innovation date replacement", we assume the physical life of an asset is effectively infinite, in the sense that technical advances make it obsolete before it suffers substantial physical deterioration, so that assets are eventually replaced due to technological advances. In the second scenario, which we call "light bulb

\footnotetext{
${ }^{8}$ See the references cited in footnote 5 .

${ }^{9}$ Justice Breyer (Verizon v. FCC, Dissent: 22), as quoted by Weisman (2002).

${ }^{10}$ For example, ILECs argue that proxy models often assume an unrealistic level of sharing of the cost of structures (i.e. poles and underground conduit facilities) with other utilities. They also argue that cost minimization procedures in proxy models assume an unattainable level of efficiency that no real world firm could expect to emulate. The results of this paper are relevant to the setting of one input factor - the firm's utilization rate of existing capacity (also called a fill factor).

${ }^{11}$ We do not, however, evaluate the realism of proxy model algorithms or attempt to recommend specific input values for use in proxy model computations. In addition, we do not specifically consider the conditions under which unbundled network elements should be offered under TELRIC prices.
} 
performance," we assume each asset has a fixed lifetime. In both scenarios, we derive cost minimizing investment plans over assumed planning horizons. These results are relevant to TELRIC cost studies and cost models generally in that they provide a method by which forward-looking capacity utilization factors (an important input in cost models) can be derived. Section 3 also shows how to compute efficient investment plans starting from existing capacity levels of an incumbent firm. To the extent that initial capacity levels can approximate the existing investment base of ILECs, these results may reconcile TELRIC price computations with "actual cost" computations favored by ILECs and some writers. Based on our derivation of efficient investment plans in the light bulb performance scenario, we also compare TELRIC pricing rules, as generally implemented, with prices defined by an efficient entry contestability criterion.

This paper does not address the criticism, raised by some observers and ILECs, concerning the appropriate cost of capital to be used in calculations like those performed herein. Specifically, some ${ }^{12}$ have argued that a competitive environment exposes ILECs to more risk than the former franchise monopoly environment. They argue that higher risk, including the risk associated with foregone option value when an investment is made, must be compensated through higher input values for the firm's cost of capital. The analysis herein makes no judgments regarding these arguments. Throughout, we treat the cost of capital as an exogenous input that has been derived via some other analysis.

Both sections 2 and 3 are based on extensive computations using Mathematica ${ }^{\mathrm{TM}}$, and details of the relevant programming code are available from the authors upon request. Some of the results of section 2 have appeared elsewhere in the academic literature, ${ }^{13}$ though they seem to be less familiar to practitioners of regulation. We view these results as tutorial in nature, and as potential computational aids for regulatory commissions faced with setting actual TELRIC prices. Section 3 presents several new results on the computation of cost minimizing investment plans and the derivation of pricing rules based on these plans.

\section{Dynamic pricing of an already-determined investment and usage plan}

The objective of this section is to compare the time paths of prices and depreciation under traditional regulatory accounting with the prices and depreciation implied by various versions of forward-looking pricing methods such as TELRIC. The analysis in section 2 assumes a single asset type with a fixed and known life of $L$ time periods. An initial investment is made at time $t=T \geq 0$ at a cost of $F_{T}$. This investment installs a fixed productive capacity per unit of time normalized for convenience to equal one unit of output. The firm's cost of capital is constant and equal to $r$ (or $100 r \%$ ) and its corresponding discount factor is $\delta=1 /(1+r)$. The asset may be under-utilized at any particular time. The percentage utilization (fill factor) at time $t$ is $q_{t}$, which is the same as the quantity produced and sold given the normalization.

Several assumptions are needed for expositional ease and to focus attention on the dynamics of pricing. We assume there is no physical depreciation and no operating cost during the life of the asset. We also assume the asset has no salvage value, either positive

\footnotetext{
${ }^{12}$ See Hausman (1997).

${ }^{13}$ See, for example, Biglaiser and Riordan (2000), Mandy (2002) and Salinger (1998).
} 
or negative, at the end of its life. Finally, we ignore taxes. All of these realistic features can be incorporated without changing the important aspects of the analysis.

While the analysis is formally concerned with the determination of a time path of prices that recovers the investment cost of a specific asset (e.g. a switch installed in a particular central office), it can be more generally applied to the determination of pricing rules for entire classes of network elements (e.g. all switching facilities offered by a particular carrier in a particular region). Since the analysis assumes a fixed and known life of length $L$, it is necessary that individual network elements priced according to the principles derived below be reasonably homogeneous assets with roughly comparable asset lives. While TELRIC models are at times employed to estimate the forward looking cost of local exchange service in total, in order to use the results of this section it is necessary to separately compute component price schedules for each class of homogeneous assets. The components can then be aggregated, if desired, to estimate the forward-looking cost of local exchange service in total.

It is important to note that the utilization rate $q_{t}$ can be either a traditional fill factor as used in a static proxy model, or alternatively a variable rate of utilization of a particular asset that might result from an investment made in anticipation of future demand growth. Throughout most of section 2 we maintain the assumption of a fixed utilization rate. Section 2.8 illustrates how certain price and depreciation schedules may change when a variable utilization rate is assumed, although the substantive conclusions reached in earlier sections continue to hold in the more general case.

\subsection{The economic depreciation identity}

There is a fundamental inviolable relationship between prices, utilization, economic depreciation, and the firm's discount factor (i.e., the firm's cost of capital). This relationship holds by definition, and is derived as follows. Let $p_{t}$ denote the price received by the asset owner at time $t$ for the asset's services, based on the convention that all variables are set at the beginning of each period. Then, once the initial investment $F_{T}$ is made, the value of the asset at any time $t \geq T$ is $V_{t}=\sum_{j=t}^{T+L-1} \delta^{j-t} p_{j} q_{j} \cdot{ }^{14}$ By definition, the economic depreciation of the asset at time $t, d_{t}$, is equal to

(1) $d_{t}=V_{t}-V_{t+1}=p_{t} q_{t}-(1-\delta) \sum_{j=t+1}^{T+L-1} \delta^{j-(t+1)} p_{j} q_{j}$ for $t=T, \ldots, T+L-1$

Equation (1) can be rewritten as $p_{t} q_{t}=d_{t}+(1-\delta) \sum_{j=t+1}^{T+L-1} \delta^{j-(t+1)} p_{j} q_{j}$ so that at time $t=$ $T+L-1$ we have $p_{T+L-1} q_{T+L-1}=d_{T+L-1}$. Recursive substitution then gives

$$
p_{t}=\frac{d_{t}+(1-\delta) \sum_{j=t+1}^{T+L-1} d_{j}}{q_{t}}=\frac{d_{t}+r \delta \sum_{j=t+1}^{T+L-1} d_{j}}{q_{t}} \text { for } t=T, \ldots, T+L-1
$$

By equation (1), for any price path $p_{T}, \ldots, p_{T+L-1}$ specified by a regulator or imposed by competitive conditions, the economic depreciation at every time in the asset's life is

\footnotetext{
${ }^{14}$ This expression explicitly depends on the absence of operating costs, salvage value, and taxes. All of these can be introduced here at the expense of additional complexity.
} 
uniquely determined. In this form, the relationship dictates the economic depreciation that will occur at time $t$ as a function of the current and future prices that are actually received, current and future expected utilization, the cost of capital $r=(1-\delta) / \delta$ allowed by the regulator or required by financial markets, and the life of the asset.

Alternatively, equation (2) expresses the fact that, if a path of depreciation $d_{T}, \ldots, d_{T+L-}$ 1 is specified by the regulator, then there is a unique price path which ensures that the chosen depreciation amounts are economic depreciation. This relationship dictates the price that must be charged at time $t$ as a function of current and future economic depreciation allowed by the regulator, current utilization, the cost of capital allowed by the regulator or required by financial markets, and the life of the asset. Equation (2) is the traditional (operating expense + depreciation + cost of capital) regulatory pricing formula, where operating expense is absent by assumption, and $r \delta \sum_{j=t+1}^{T+L-1} d_{j}$ is the opportunity cost of carrying the as-yet un-depreciated balance from time $t$ to time $t+1$. When equations (1) and (2) hold, the firm is by definition earning a rate of return equal to its target rate of return $r$.

If we assume that a price path and a depreciation schedule are both specified by a regulator or a combination of a regulator and competitive conditions, then equations (1) and (2) may no longer hold, and the firm's target rate of return can no longer be independently specified by a regulator or by financial markets. The implied rate of return from time $t$ to the end of the useful life, however, is given implicitly by rewriting expression (2) (taking its present value from time $t$ to the end of the life) as ${ }^{15}$

$$
\sum_{i=t}^{T+L-1} \delta^{i-t}\left[p_{i} q_{i}-d_{i}-(1-\delta) \sum_{j=i+1}^{T+L-1} d_{j}\right]=0 \text { for } t=T, \ldots, T+L-1
$$

Although this final expression cannot be solved explicitly for $\delta$ (unless the allowed prices and depreciation, and expected utilizations, are solvable functions of time), it implicitly dictates the cost of capital (i.e., discount factor) that will be earned from time $t$ through time $T+L-1$ as a function of current and future economic depreciation allowed by the regulator, current and future prices allowed by the regulator or imposed by competitive conditions, current and future expected utilization, and the life of the asset. In particular, this expression determines the cost of capital actually earned, even if a regulator uses some other cost of capital in calculating allowed prices and allowed economic depreciation. Whether the cost of capital actually earned is consistent with that used by a regulator in calculating prices and/or depreciation depends on whether the regulator's price and depreciation calculations are consistent with this identity. The cost of capital actually earned can be found as a numeric solution to equation (3), using Mathematica ${ }^{\mathrm{TM}}$ or similar software packages.

\subsection{Three Stylized Scenarios}

For illustration purposes we consider three stylized scenarios. In each scenario we assume that an initial investment is made at time $T=0$, at a cost of $F_{0}=100$. This cost is assumed to change at a constant annual rate $\lambda$ (or $100 \lambda \%$ ) in years $t>0$. The cost of capital is $r=$

\footnotetext{
${ }^{15}$ At the time of investment, $T$, this reduces to $\sum_{j=T}^{T+L-1} \delta^{j-T} p_{j} q_{j}=\sum_{j=T}^{T+L-1} d_{j}$.
} 
$11.25 \%$ per year. In the first scenario $\lambda$ is zero. This is a benchmark case that we use to compare traditional regulatory pricing (i.e., equation 2) with TELRIC pricing, without the complications created by cost dynamics. ${ }^{16}$ In the second scenario $\lambda$ is negative. Such initial investment cost decreases might be caused, for example, by technological improvements embodied in the firm's capital assets. This scenario can be thought of as representative of switching assets. In the third scenario $\lambda$ is positive. Such initial investment cost increases might be caused, for example, by general inflation. This scenario can be thought of as representative of outside plant. In the remainder of this section we let $\gamma=1+\lambda$, so the initial investment cost at any time $t=T$ is $\gamma^{T} F_{0}$.

\subsection{Benchmark case: Traditional revenue recovery versus TELRIC}

For the benchmark case, in addition to assuming that $\lambda=0$, we use an economic life $L=$ 12 and a utilization rate $q_{t}=0.8$ for all $t=0, \ldots, L-1$.

\subsubsection{Traditional price path based on straight line depreciation}

Under traditional historical cost-based regulatory accounting, both investments and operating expenses for the regulated firm are recorded on an annual basis. ${ }^{17}$ Price in each year for the life of a given asset is then computed as the sum of operating expense plus capital cost, where capital costs are equal to the sum of depreciation and a return on undepreciated assets. If straight-line economic depreciation is assumed then $d_{t}=F_{0} / L$ for $t$ $=0, \ldots, L-1$. Hence, (since we are ignoring operating expenses) the price that must be charged at time $t$ to implement straight-line depreciation, while allowing cost of capital $r=$ $(1-\delta) / \delta$, is found by substituting the expression for straight-line depreciation into equation (2). This price path is illustrated in Figure 1.

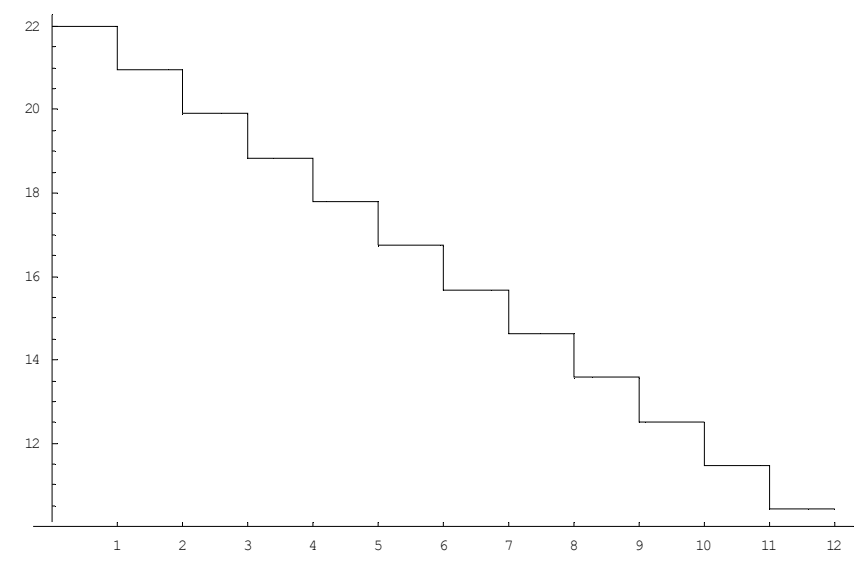

Figure 1: Traditional prices under straight line depreciation: case of constant investment cost

\footnotetext{
${ }^{16}$ We note that under traditional regulatory accounting, prices are based on the traditional interpretation of economic depreciation (i.e., equation (2)) applied to an aggregation of all the firm's assets. Since under historical cost accounting, assets of different vintages are included in this calculation, the specific price and depreciation schedules discussed below are unlikely to hold in the aggregate.

${ }^{17}$ This representation of traditional regulatory accounting is admittedly a caricature. Rate reviews do not necessarily occur annually, and in some cases explicit levelization of rates is imposed.
} 
Assuming straight-line depreciation, the price decreases over time because the as-yet un-depreciated balance decreases over time, and consequently the cost of capital applied to that balance decreases over time.

\subsubsection{Levelized TELRIC price for the life of the asset}

While traditional pricing is fundamentally backward-looking, TELRIC pricing is designed to be forward-looking. In addition, TELRIC prices can be defined in various ways, depending on the extent to which regulators incorporate expectations about the future. A TELRIC price is defined so as to recover the initial investment cost $F_{0}$ when the utilization path is $q_{j}$, provided the price remains in effect for the life of the asset. The basic formula for the level TELRIC price, $p T E L R I C_{0}$, that recovers an initial investment cost $F_{0}$ made at time 0 over an asset life $L$ and with discount factor $\delta$, is:

(4) pTelric $0=\frac{F_{0}}{\sum_{j=0}^{L-1} \delta^{j} q_{j}}$.

Figure 2 shows a comparison of the levelized TELRIC price with traditional prices based on straight-line depreciation.

Equation (4) differs in two ways from TELRIC calculations used in practice. First, many existing cost models, such as the FCC's Synthesis Model, include assumptions on depreciation schedules to derive the numerator of (4). ${ }^{18}$ This is superfluous since the present value of the actual investment is known to be $F_{0}$ (it has to be known before it can be depreciated and then expressed in present value). Actual economic depreciation when the level TELRIC price (4) is received over the life of the asset is given by (1) evaluated at the price (4), even if some other depreciation schedule is used to derive the numerator $F_{0}$. Second, variable utilization rates are not assumed in the FCC's Synthesis Model. The impact of variable utilization rates is studied in section 2.8 below.

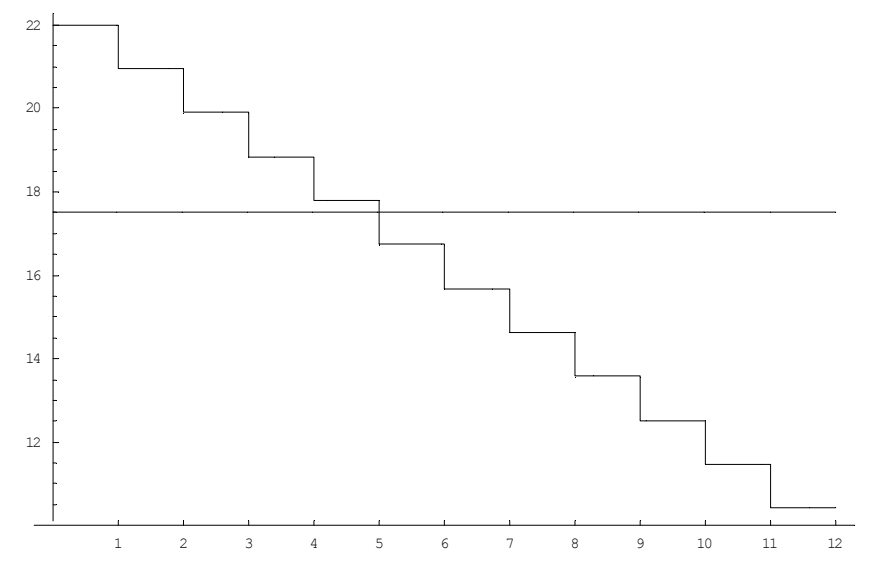

Figure 2: Levelized TELRIC versus traditional prices: case of constant investment cost

\footnotetext{
${ }^{18}$ In particular, depreciation schedules are used to derive the capital carrying cost for each year in an asset's life. However, the resulting annual charge factor used by the model uses only the present value of this schedule.
} 
The levelized TELRIC price implies a path of economic depreciation given by equation (1) above. The resulting depreciation schedule is necessarily rising, given a constant utilization rate, since the first term in equation (1) is constant while the second term is increasing in $t$. Figure 3 shows that levelized TELRIC pricing substantially decelerates economic depreciation compared with traditional pricing based on straight-line depreciation.

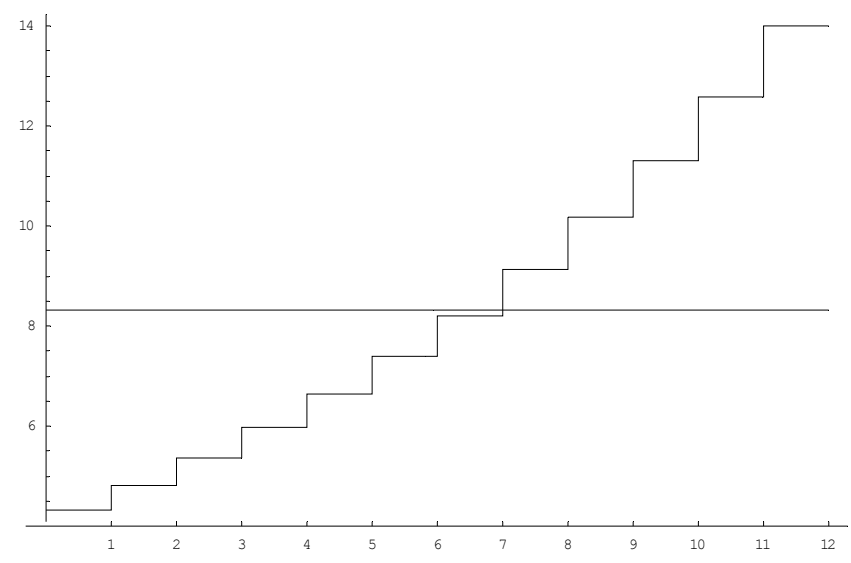

Figure 3: Depreciation under levelized TELRIC and traditional pricing: case of constant investment cost

Whenever the firm's price schedule and depreciation schedule are chosen to satisfy equations (1) and (2), the firm's earned rate of return from the time the asset is acquired is necessarily equal to the target cost of capital used by the regulator in computing these schedules. This can be verified by computing explicit numerical solutions of equation (3). For any $t, 0 \leq t \leq \mathrm{L}$, if TELRIC prices are set according to equation (4) and the depreciation schedule satisfies equation (1) for these prices, then the earned rate of return from time $t$ to the end of the asset's life is equal to $11.25 \%$. The same result holds when the depreciation schedule is straight line and prices are set to satisfy equation (2) for these depreciation values. In addition, even though the levelized TELRIC price and straight line depreciation do not jointly satisfy equations (1) and (2), together they imply that the firm earns the target rate of return over the entire life of the asset (i.e. from $t=0$ to the end of the asset's life).

\subsection{Levelization in cost proxy models and the impact of changing investment cost}

The illustrations in the previous section show that the levelization technique used to calculate TELRIC prices dramatically changes economic depreciation, but nonetheless can produce prices that exactly recover the initial cost of an asset and a target rate of return.

When initial investment cost is changing, however, this consistency of TELRIC depends on how the TELRIC calculation is applied over time. If TELRIC prices are subject to periodic reviews that are shorter than asset lives, the prices will not generally recover exactly the initial cost of the asset and the cost of capital used in deriving the TELRIC prices. By "periodic reviews" we mean that the TELRIC price is reset based on a then-current initial investment cost. 
In particular, when investment cost is changing at the constant rate $\lambda=\gamma-1$, the cost of investment at any time $t$ is $\gamma^{t} F_{0}$. Assuming the utilization path is invariant to the date of installation, levelized TELRIC prices for an investment made at any time $t=T \geq 0$ are then given by:

(5) pTelric $_{T}=\frac{\gamma^{T} F_{0}}{\sum_{j=0}^{L-1} \delta^{j} q_{j}}$.

Comparison of equations (4) and (5) reveals that, if investment cost is constant (so that $\gamma=1$ ), then the levelized TELRIC price $p T E L R I C_{T}$ is equal to $p T E L R I C_{0}$ for any $T$. Otherwise, a periodic review at time $t$ that bases the levelized TELRIC price on thencurrent initial investment cost will change the levelized TELRIC price to $p T E L R I C_{T}$.

Sections 2.5 and 2.6 consider the impact of TELRIC rate setting methodologies when the firm does not receive the initial TELRIC price for the entire life of the asset. Specifically, we focus on a three-year review period, which is significantly shorter than the assumed life of most network elements. In this case, the consistency properties found in section 2.3 no longer hold. In section 2.7 , however, we show that consistency can be restored by applying a straightforward correction factor based on a price path that recovers the target revenue and the time path of utilization rates. When the correction factor is applied to the TELRIC price path of interest, corrected prices exactly recover the initial cost of the asset and a target rate of return.

In section 2.7 we also derive a contestable pricing rule. In the absence of entry barriers, the contestable price path would represent a constraint on the regulated firm's prices that is in many ways similar to the constraint implied by periodic TELRIC reviews. The same correction factor discussed above can guarantee that the firm earns its target cost of capital in these situations even when its prices must closely follow a time path dictated by external competitive conditions.

\subsection{Decreasing initial investment cost}

Consider now the second scenario, in which an investment is made at time $T=0$ and initial investment cost is decreasing at the rate $\lambda$. We use values that are intended to be representative of end-office switching, including an asset life of $L=16$ years, a constant utilization rate of $q_{t}=0.94$, and an annual $-10.98 \%$ rate of decrease in initial investment cost. Therefore $\gamma=0.8902 .{ }^{19}$

Figure 4 compares TELRIC prices reviewed every three years with traditional prices based on straight-line depreciation. As Figure 4 indicates, TELRIC prices subject to three-year reviews understate traditional prices in every year. Note that neither traditional prices nor TELRIC prices computed at each review period account for the rate of decline of investment cost in future years. While this does not create a problem in the case of traditional pricing, since it is designed to recover the historical cost of the asset over its

\footnotetext{
${ }^{19}$ These values are derived from a study done as part of an FCC order which established input values for the cost proxy model used in that proceeding (Federal-State Joint Board on Universal Service, ForwardLooking Mechanism for High Cost Support for Non-Rural LECs, Tenth Report and Order, CC Docket Nos. 96-45, 97-160, FCC 99-304, 1999). The assumed rate of change of switching investment cost derived from that report is used for illustrative purposes only, and no attempt has been made to update or verify those findings.
} 
lifetime, it creates a problem for TELRIC computations subject to a three-year review. More specifically, the TELRIC computation ignores the impact of future cost reviews on prices during the life of the asset, instead incorrectly assuming the initial levelized TELRIC price will continue to be received for the entire life of the asset. Thus, while the TELRIC price computed in year 0 was computed to fully compensate the firm for its investment costs made in year 0 , it does so only if maintained throughout the life of the asset. If prices are reduced in future years due to the lower investment costs at future TELRIC cost reviews, then the resulting price schedule no longer fully compensates the firm.

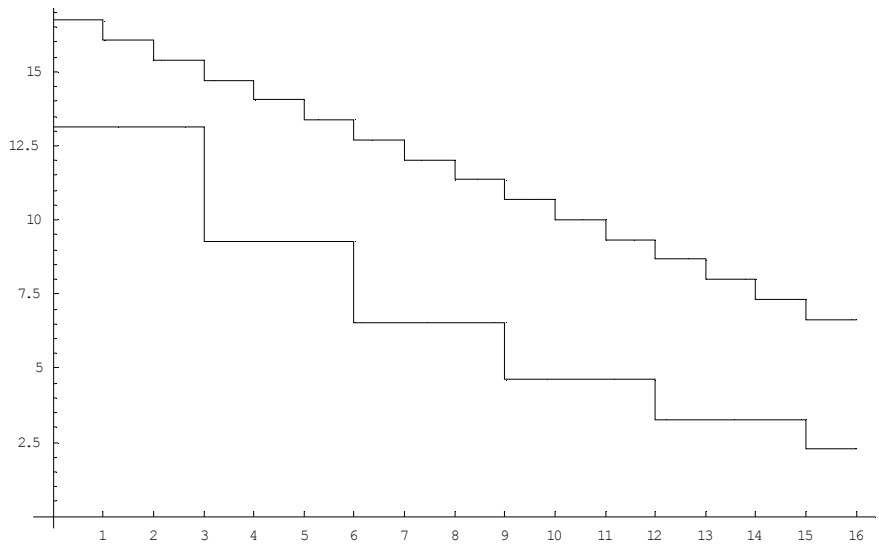

Figure 4: Traditional and triennially reviewed TELRIC prices: case of decreasing investment cost

Figure 5 compares TELRIC economic depreciation and straight-line depreciation. While in the benchmark analysis, depreciation under TELRIC pricing was increasing over time (see Figure 3), the economic depreciation identity (1) now reveals a secularly decreasing depreciation schedule under TELRIC that increases only within each review cycle. This is because the periodic reviews with decreasing investment cost produce TELRIC prices that fall fast enough in this example to more than offset the decelerated depreciation caused by levelization.

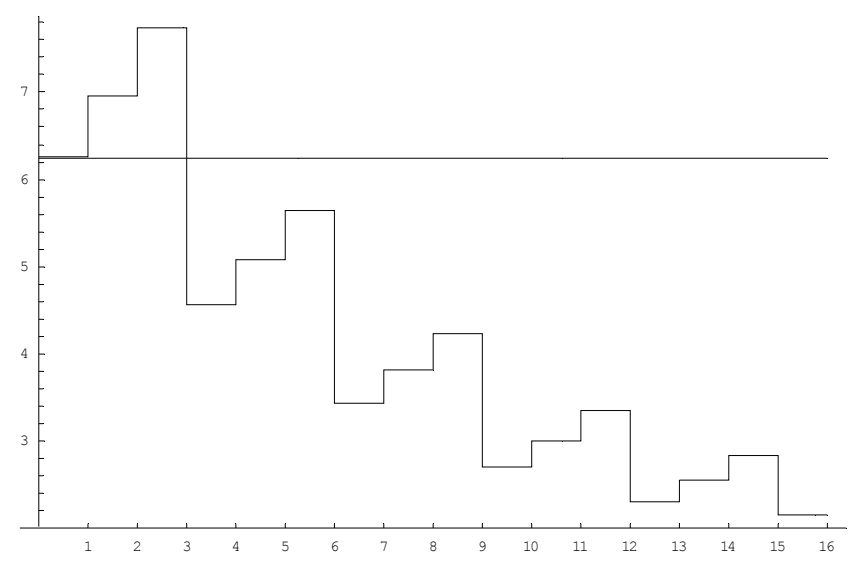

Figure 5: Straight line and implied depreciation under triennial TELRIC reviews: case of decreasing investment cost 
If a regulator chooses to impose TELRIC prices, subject to a three year review and straight line economic depreciation, the earned rate of return over the life of the asset is substantially below the regulator's assumed level, in this case approximately $1.15 \%$ instead of the target rate of $11.25 \%{ }^{20}$

\subsection{Increasing initial investment cost}

Consider now the third scenario, in which an investment is again made at time $T=0$, and initial investment cost is increasing at the rate $\lambda$. We use values that are intended to be representative of loops, including an asset life of $L=30$ years, a utilization rate of $q_{t}=$ 0.70 (assumed to represent average utilization over the life of the asset) and an annual increase in the cost of investment (due to inflation) equal to $3 \%$, so that $\gamma=1.03 .{ }^{21}$

Figure 6 compares TELRIC prices that are reviewed every three years with traditional prices based on straight-line depreciation. The TELRIC prices now increase, understating traditional prices early in the life of the asset but substantially overstating traditional prices during most of its life.

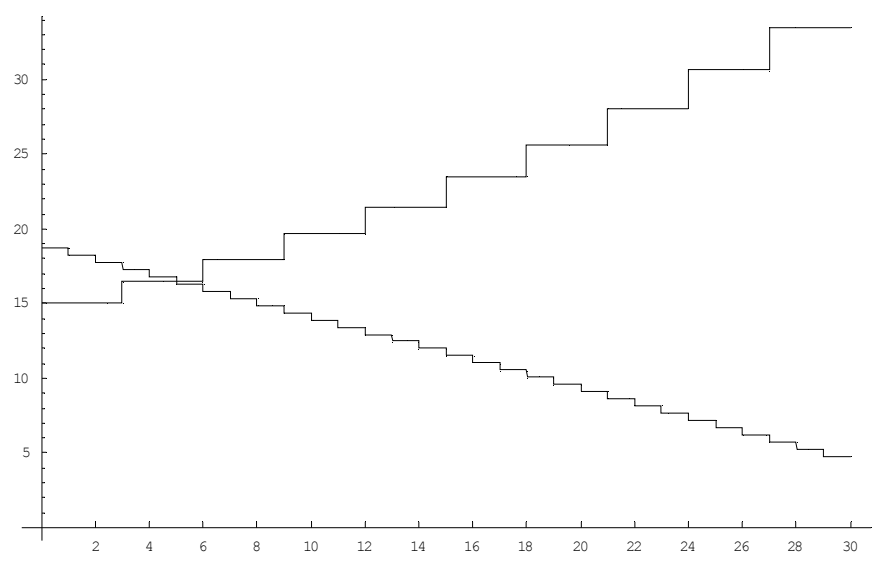

Figure 6: Traditional and triennially reviewed TELRIC prices: case of increasing investment cost

The economic depreciation implied by TELRIC, as shown in Figure 7, is now severely decelerated, to the point that it is negative in the early years after the investment. This is because the deceleration caused by levelization is reinforced by the decelerating effects of rising prices. Rising prices decelerate economic depreciation for two reasons. First, other things constant, economic depreciation is higher when prices are higher. Recall that economic depreciation is simply the change in the value of the asset from one period to the next. As equation (1) indicates, however, the drop in the value of the asset is equal to the

\footnotetext{
${ }^{20}$ If TELRIC reviews are conducted annually instead of on a three-year basis then under the present assumptions the earned rate of return is negative. In this case, the firm does not recover even the initial cost of the asset.

${ }^{21}$ These values are used for illustrative purposes only, and do not represent values that have been verified as reasonable for loop investments.
} 
revenue received in the period. ${ }^{22}$ Thus, if prices rise, revenue will rise, which will increase depreciation.

Second, as time passes discounting takes a progressively lighter toll on the present value of the as-yet unrealized relatively high late-life prices. Even with only 3 percent growth and triennial reviews, prices are so high at the end of thirty years compared to the initial prices (over twice as high) that the value-enhancing effect of moving them one year closer in time can be larger than the revenue actually received in an early year. Hence value can actually increase over time. An increase in value that occurs without additional investment is negative economic depreciation. This second factor is responsible for the negative economic depreciation observed in Figure 7.

Finally, if the triennially reviewed TELRIC prices and straight line economic depreciation are both imposed by the regulator, the earned cost of capital over the life of the asset is equal to $14.18 \%$, which is substantially above the target rate of $11.25 \%$.

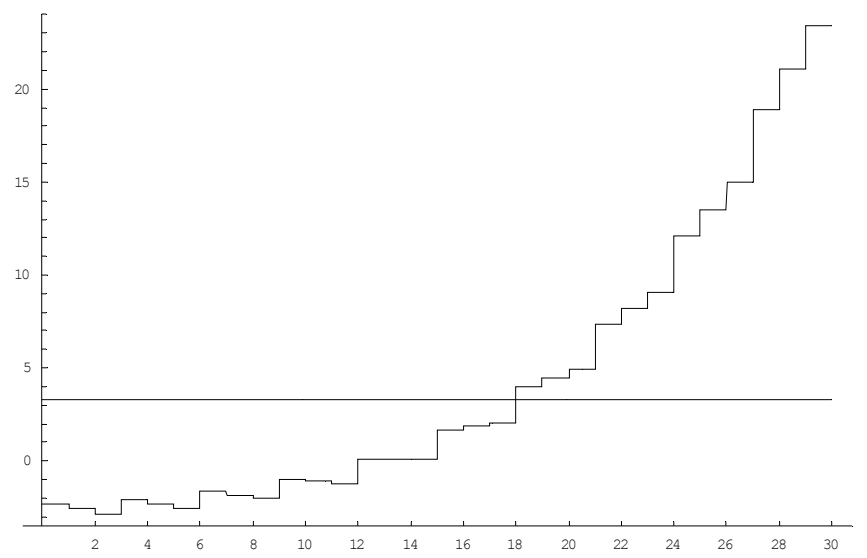

Figure 7: Straight line and implied depreciation under triennial TELRIC reviews: case of increasing investment cost

\subsection{TELRIC corrections and contestable price paths}

As mentioned in section 2.4, a correction factor can be applied to ensure that the earned cost of capital is equal the target rate used when calculating TELRIC prices and depreciation. The correction factor is simply the ratio of desired revenue to revenue resulting from the TELRIC price path, or any other price path in which the "pattern" of prices is desired, both expressed as present values at the investment time $T$. Corrected prices are then computed by multiplying the "pattern" price in each time period by the correction factor. Formally, the correction factor for an investment made at time $T$ is defined as follows:

$$
\text { correction }_{T}=\frac{\sum_{j=0}^{L-1}\left(\delta^{j} p \operatorname{Re} \text { venue }_{T+j} q_{T+j}\right)}{\sum_{j=0}^{L-1}\left(\delta^{j} p \text { Pattern }_{T+j} q_{T+j}\right)} .
$$

\footnotetext{
${ }^{22}$ Prior to time $t$, the revenue $p_{t} q_{t}$ is in the asset's future and therefore contributes to its value. After time $t$, however, the revenue $p_{t} q_{t}$ is no longer in the asset's future, so the asset must lose value $p_{t} q_{t}$ at time $t$.
} 


\subsubsection{Decreasing initial investment cost}

We first consider the case of falling investment cost as specified by the parameter values in section 2.5. We can correct the TELRIC prices that are reviewed every three years so that they deliver the same revenue as the traditional prices. ${ }^{23}$ A numerical computation of equation (6) reveals that the correction factor in this case is 1.5014. Thus, given the parameter values assumed in scenario 2 and a three year review process, TELRIC switching prices should be increased by approximately $50 \%$ in order to allow the incumbent firm to recoup its costs and earn the target rate of return on a forward looking basis.

Figure 8 illustrates both corrected (solid line) and uncorrected (dashed line) TELRIC prices compared to traditional prices (dotted line). The corrected TELRIC prices begin above but quickly fall below traditional prices, reflect the difference in three year versus one-year review, and have the same pattern as the uncorrected TELRIC prices.

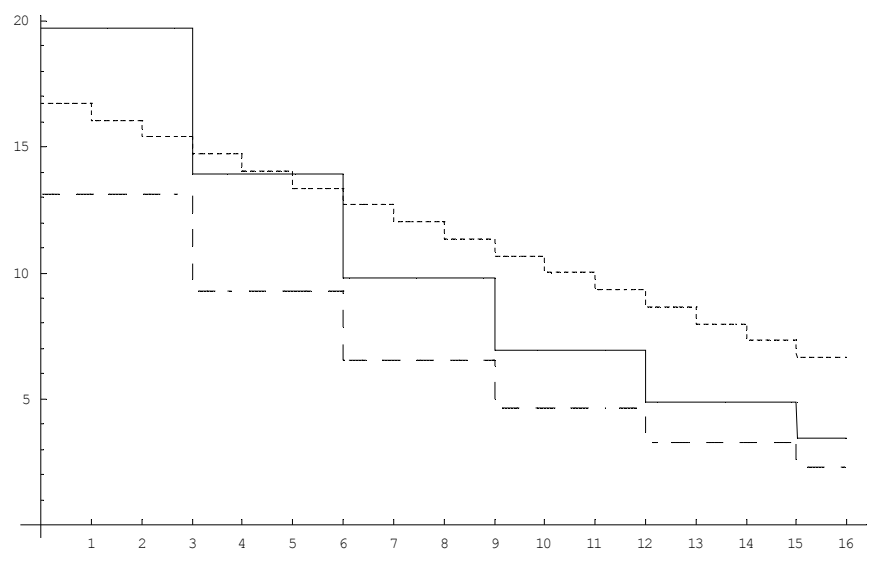

Figure 8: Traditional versus corrected and uncorrected triennially reviewed TELRIC prices: case of decreasing investment cost

By construction, the corrected TELRIC prices also deliver the regulator's target cost of capital, equal to $11.25 \%$ in the present case.

\subsubsection{Increasing initial investment cost}

These same comparisons between traditional and TELRIC prices can be made when investment cost is increasing, using the parameter values in section 2.6. The TELRIC correction factor is now 0.802743 . That is, assuming the parameter values in scenario 3 and a three year review period, TELRIC loop prices should be reduced by approximately $20 \%$ in order to allow the incumbent firm to recoup its cost and earn the target rate of return on a forward looking basis. The corrected TELRIC prices, again shown as a solid line in Figure 9, begin below but rise above traditional prices after less than one-third of the life, again reflect the difference between three-year versus one-year reviews, and again have the same pattern as the uncorrected TELRIC prices.

\footnotetext{
${ }^{23}$ Since only the present value of total revenues are relevant in (6), the same correction would result for any Revenue and Pattern price paths having the same present value revenues.
} 


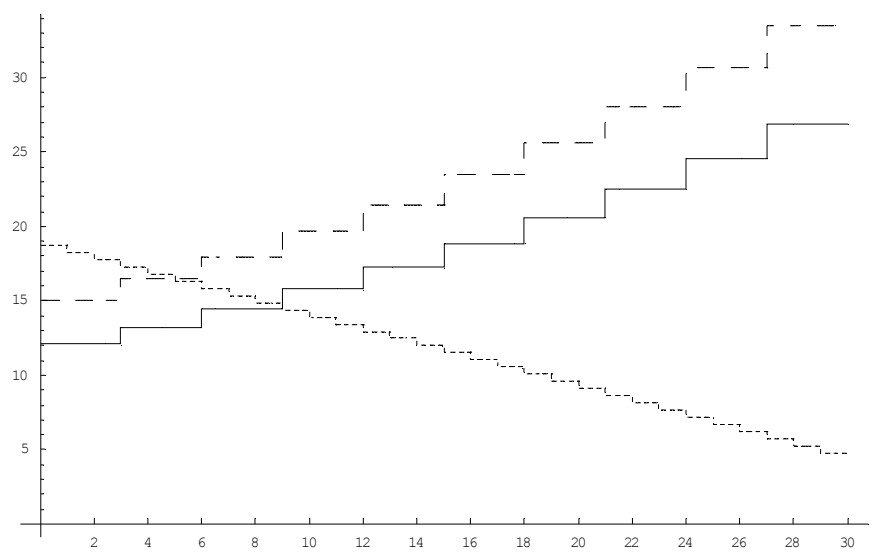

Figure 9: Traditional versus corrected and uncorrected triennially reviewed TELRIC prices: case of increasing investment cost

\subsubsection{Contestable price paths}

So far we have compared TELRIC prices, both uncorrected and corrected, with traditional regulatory prices. We have not considered whether those prices emulate or equal equilibrium prices that would result in a competitive market with potential entry in every time period. Competitive markets generally provide efficient entry and investment signals to both incumbents and new entrants. Regulated prices that do not at least emulate competitive equilibrium prices may therefore fail to give efficient investment incentives to incumbents and new entrants. Thus, if one wants TELRIC prices to provide efficient entry and investment signals, it is desirable that they emulate competitive equilibrium prices. This section addresses this issue.

Competitive equilibrium prices are usually defined as prices that equate aggregate supply and aggregate demand when buyers and sellers all act as price-takers. Such prices do not generally exist when production (in the present environment, capacity acquisition) has increasing returns to scale. Although we have not yet considered the relationship between the productive capacity installed at time $T$, which is normalized in the present section at 1 , and its cost $\gamma^{T} F_{0}$, many telecommunications assets have substantial increasing returns in capacity acquisition. We explicitly consider increasing returns cost structures in section 3. Hence, in that context we cannot define true competitive equilibrium prices.

However, the important feature of competition that provides incentives for efficient entry and exit is that economic profit is zero for efficient incumbents and efficient potential entrants no matter when entry is contemplated. Prices with this property are well-defined even when capacity acquisition has increasing returns to scale. For lack of a better term, we call such prices "contestable," although it is important to realize that we are requiring social cost efficiency as part of this definition.

As with the TELRIC prices defined in (5), we continue to assume: 1) the utilization path is invariant to the date of installation, 2) contestable prices are set at the beginning of each year and remain constant during the year, and 3) $\gamma^{T} F_{0}$ is the efficient cost of a 
capacity unit installed at time $t=T$. Then, if the target discount factor $\delta$ reflects a competitive rate of return, contestable prices are defined by the breakeven condition

$\sum_{j=0}^{L-1} \delta^{j} p$ Contestable $_{T+j} q_{j}=\gamma^{T} F_{0}$ for $T=0,1,2, \ldots$

The solution to this equation is: ${ }^{24}$

(7) Contestable $_{T}=\frac{\gamma^{T} F_{0}}{\sum_{j=0}^{L-1}(\delta \gamma)^{j} q_{j}}$ for $T=0, \ldots, L-1$.

Compared with equation (5), the contestable price at time $T$ accounts for the fact that future prices will be different when costs are not constant (i.e., $\gamma \neq 1$ ), whereas the TELRIC price does not anticipate future price changes.

Assuming utilization is constant, equation (7) shows that the contestable prices decrease over time when investment cost is decreasing (i.e., $\gamma<1$ ) and increase over time when investment cost is increasing (i.e., $\gamma>1$ ). These are the same secular trends displayed by TELRIC prices that are reviewed every three years. Moreover, as we have already seen, the corrected TELRIC prices yield the target rate of return. Hence the triennially reviewed corrected TELRIC prices indeed emulate contestable prices. Figures 10 and 11 present the comparisons for scenarios 2 and 3, respectively. The only significant difference is due to the timing of three-year TELRIC reviews versus the (assumed) annual adjustment of contestable prices.

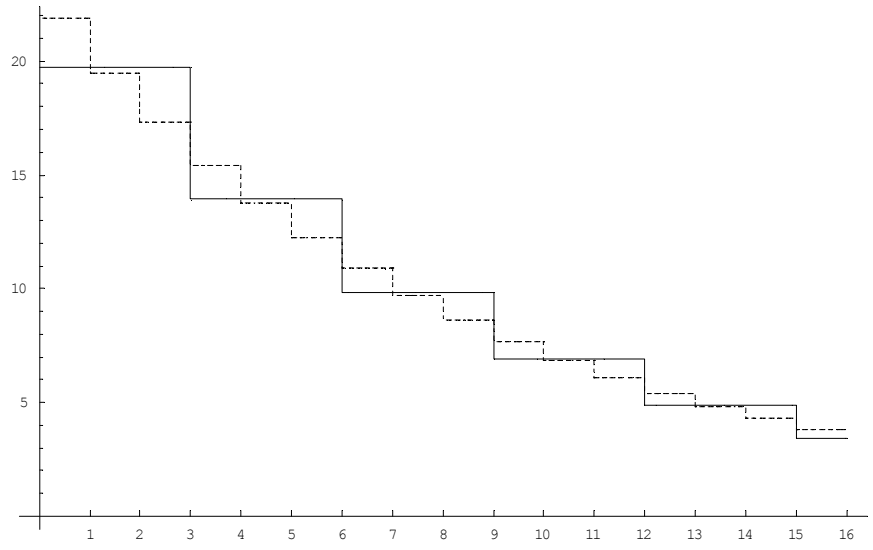

Figure 10: Contestable versus corrected triennially reviewed TELRIC prices: case of decreasing investment cost

\footnotetext{
${ }^{24}$ See also Mandy 2002 Theorem 1, wherein utilization is assumed to be unity and constant returns to scale is assumed.
} 


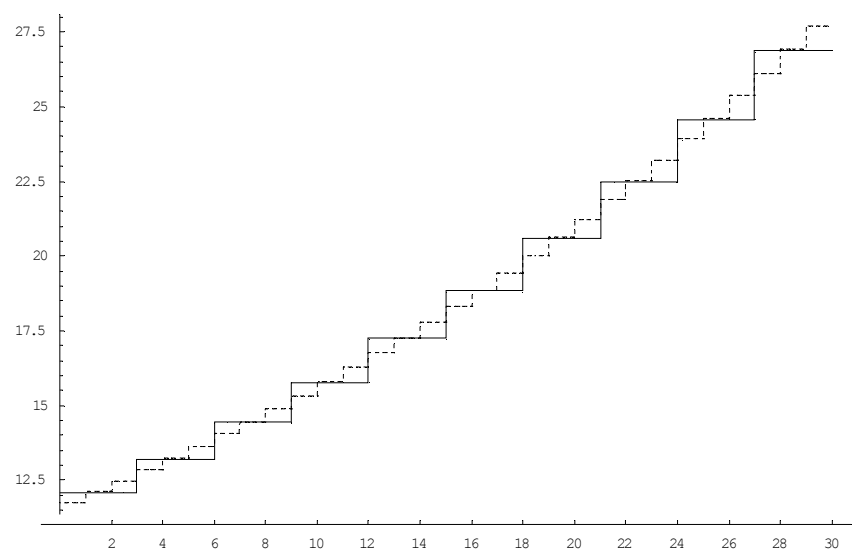

Figure 11: Contestable versus corrected triennially reviewed TELRIC prices: case of increasing investment cost

\subsection{Variable utilization rates}

All computations up to this point have assumed a constant utilization rate. If demand is growing, a cost-minimizing firm may make investments in anticipation of future growth, in which case utilization rates will increase as the asset ages. All of the definitions of previous sections are valid under these conditions, although the specific time paths of price and depreciation will change when utilization rates are not constant.

However, when utilization rates are not constant, a discrepancy emerges between the TELRIC pricing rule (5) and the TELRIC prices actually calculated by cost proxy models, such as the FCC's synthesis model. Specifically, the Synthesis Model uses average utilization to calculate the TELRIC price, rather than anticipating that utilization will change over the life of the asset. In addition, the size of the investment $F_{0}$ is assumed to be sufficient to satisfy current demand divided the utilization factor. These issues will be explored further in the following section. ${ }^{25}$

In this section, we assume increasing investment cost using the same parameter values as in section 2.6, except that we assume a growing utilization rate given by $q_{t}=.40+.55 t$ / (L-1) for $t=0, \ldots, L-1$. This utilization path models loops that are used at $40 \%$ of capacity when installed but whose usage increases linearly to $95 \%$ at the end of the thirty year life.

Figure 12 below compares three separate price paths: traditional prices (solid line), contestable prices (dotted line), and TELRIC prices reviewed every three years (dashed line). The traditional prices still fall, as when the utilization rate is constant, but now they begin much higher and decrease faster. This is because the traditional rule only uses utilization in period $t$ to calculate the price in period $t$, so the price must drop to offset growing quantity. This effect reinforces the downward slope caused by straight-line depreciation. In contrast, the contestable and TELRIC prices still increase over time

\footnotetext{
${ }^{25}$ In the present section, the function $q$ has served both as a utilization rate and as a proxy for potentially varying demand conditions. When an efficient investment plan requires repeated investments made over a planning horizon, there is no longer a simple relationship between utilization rates and aggregate demand. In section 3, these issues are treated in a more general framework in which demand is the exogenous variable and utilization rates are determined through cost minimization.
} 
because they take account of the entire utilization path to calculate the price at each time (see equations 5 and 7). Hence their dynamics are driven entirely by the growth rate of initial investment cost. Both paths are higher than under scenario 3, where utilization rates are constant, reflecting the fact that average utilization over the life of the asset is about the same as scenario 3 but revenues are delayed because utilization is initially low.

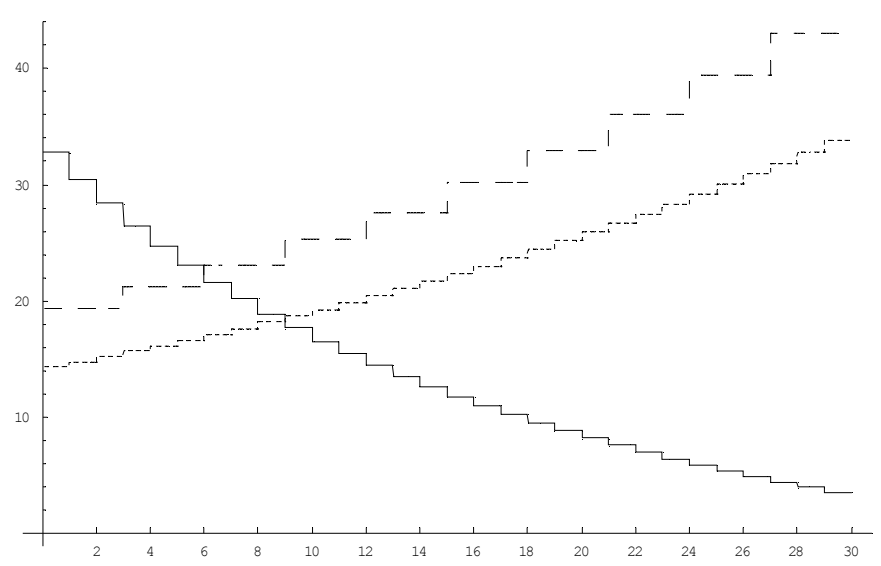

Figure 12: Traditional, contestable, and triennially reviewed TELRIC prices: case of increasing investment cost and increasing utilization

As before, the TELRIC prices can be corrected so that they yield the same rate of return as the traditional and contestable prices. The correction factor in this case is 0.761538 , which is not much different from scenario 3. The corrected TELRIC prices (solid line) again track the contestable prices (dotted line), as shown in Figure 13, and as expected, the corrected prices yield the target rate of return of $11.25 \%$.

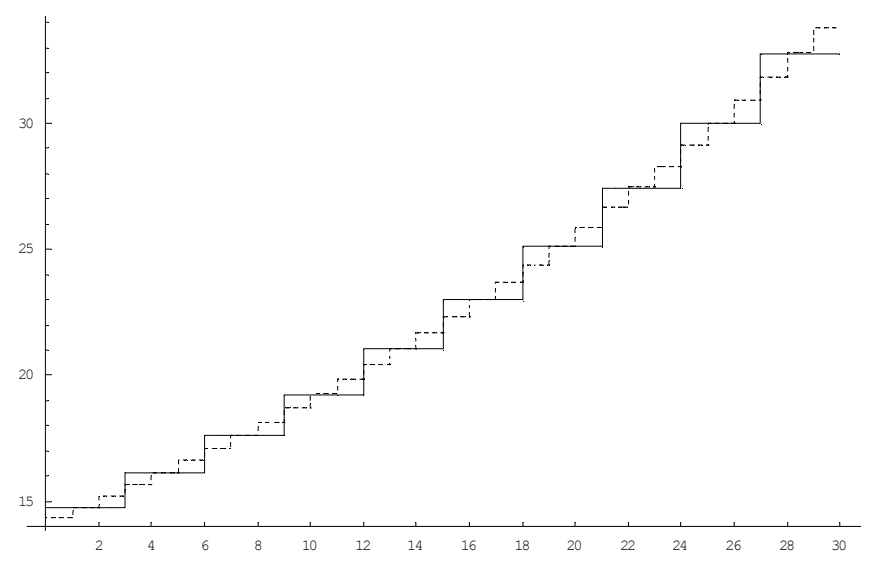

Figure 13: Contestable and corrected triennially reviewed TELRIC prices: case of increasing investment cost and increasing utilization 
We note in conclusion that these results demonstrate that demand growth as well as changing investment cost must be considered when setting a time path of prices. ${ }^{26}$ Generally, a firm's utilization rate at any point in time is determined by a solution to a cost minimization problem. The cost minimum determines the time and level of investments needed to satisfy demand at every future point in time. It may very well involve intentional under-utilization that varies over time. We consider some of these issues in the next section in a framework in which efficient investment decisions can be determined when the rate of demand growth is explicitly modeled, and a more general investment cost function is introduced.

\section{Efficient dynamic investment}

Section 2 was concerned with the time path of TELRIC prices that could be used to recover the cost of an arbitrary investment $F_{0}$ that has an arbitrary utilization path $q_{t}$. There, it was assumed the investment cost and utilization path had already been determined.

Actual investment cost and utilization of assets subject to TELRIC pricing result from decisions made by incumbent suppliers. An efficient supplier makes such decisions to minimize the cost of serving an evolving expected demand, given the expected costs of raw inputs, the expected evolution of those costs, the expected performance of the assets over time, the cost of capital and other input prices. These are dynamic cost-minimizing investment decisions.

The prices discussed in section 2 can be expected to provide incentives for efficient entry and exit provided they are based on efficient investments. Accordingly, in this section we characterize, in some cases, the dynamic cost minimizing investment decisions of an efficient firm. Under our stated assumptions, these investment decisions can be used in the corrected TELRIC pricing rules of section 2 to provide incentives for efficient entry and exit. Interest here centers on the efficient investment plan and its utilization path, which was part of the analysis throughout section 2 but only allowed to vary in section 2.8. In the present section, we introduce explicit demand growth and input cost dynamics, and then derive the investment plan and utilization path as the solution to a cost minimization problem for the firm.

We do this under two stylized scenarios about the performance of assets over time. The scenarios differ in the assumption made about asset obsolescence. In scenario 1, which we label "expected innovation date" replacement, we assume that an asset's physical life is so long relative to the pace of innovation that the physical life is not a constraint on the firm's use of the asset. In other words, assets are replaced only when technical progress either reduces operating cost or improves quality and performance of replacement assets enough to make old assets economically obsolete, even though old assets still function as they did when new. This scenario is broadly representative of switching assets.

In scenario 2, which we label "light bulb" replacement, we assume that an asset has a fixed and known physical life equal to $L$ years. During this life there is no deterioration of an asset's productivity, but at the end of its life the asset suddenly and permanently ceases to be productive. Here, an asset's physical life is the constraint on the firm's use of that

\footnotetext{
${ }^{26}$ While the asset's utilization rate has been allowed to vary in the present section, the aggregate level of capacity has remained constant at a normalized value of one unit.
} 
asset. Replacement of such assets occurs when they reach a certain age, rather than at a certain date irrespective of age as in scenario 1 . Scenario 2 is broadly representative of loop assets. ${ }^{27}$

In spite of the rudimentary nature of these computations, they may suggest both a plausible range of utilization factors for efficient telecommunications firms in a forwardlooking environment, and perhaps more importantly the way these factors depend on the assumed underlying parameters. ${ }^{28}$

\subsection{Maintained assumptions}

As in section 2, an initial investment is made at time $t=T_{1} \geq 0$. Subsequent investments are made at times $T_{2}, T_{3}, \ldots$, which are numbered in chronological order. Each investment installs a fixed productive capacity per unit of time that depends on the size of the investment. Generally, we denote by $F(I, t)$ the investment required at time $t$ to install productive capacity $I$ per unit of time. For example, the investment $F_{0}$ studied in section 2 is given by $F_{0}=F(1,0)$ since it was installed at time zero and its capacity was normalized to one. The investment times $T_{k}$ and the productive capacity $I_{k}$ installed at each investment time are chosen to minimize cost.

We assume a simple multiplicatively separable structure for $F$, and that $F$ changes over time at the constant continuous rate $\lambda$. Hence $F(I, t)=f(I) e^{\lambda t}$, where $f(I)$ is the investment required to install productive capacity $I$ at time 0 . Depending on its shape, the investment cost function $f(I)$ may reflect different returns to scale in the activity of capacity installation. It will be parameterized below for each of the two scenarios to reflect the increasing returns typical of switch and loop installation.

The firm's cost of capital is still constant and equal to $r$ (or $100 r \%$ ), which we continue to assume is $11.25 \%$ per year, implying a continuous rate of $r=0.1066$. Also, as in section 2, we continue to assume there is no physical depreciation, operating cost, or salvage value; and we ignore taxes. Again, all of these realistic features can be incorporated without changing the important aspects of the analysis.

Demand begins at time $t=0$ at an initial level $Q(0)$ and grows at the constant continuous rate $\eta \geq 0$. Hence, demand at time $t \geq 0$ is $Q(t)=Q(0) e^{\eta t}$.

Efficient dynamic investment decisions in this environment must balance two competing incentives. First, the time value of money gives an incentive to delay investments. Second, increasing returns in capacity acquisition gives an incentive to acquire capacity in large amounts, when it is acquired, thereby driving down the average cost of a unit of capacity. The first incentive implies that an efficient firm will never acquire capacity if it already possesses unused capacity. ${ }^{29}$ The second incentive implies that, when acquiring capacity, an efficient firm will install more than is needed to satisfy current demand. At each investment date, some additional capacity will be acquired in

\footnotetext{
${ }^{27}$ More general interpretations of this scenario are possible, in which the asset life is fixed but only the expected life of the asset is known to the regulator (and possibly to the firm). We do not pursue them here.

${ }^{28}$ While we do not intend for the results of this section to be directly applied to input selections for cost proxy models, such as the Synthesis Model, we believe this discussion can inform the process of choosing those inputs.

${ }^{29}$ Our results do not attempt to estimate the efficient level of so-called "administrative fill" - i.e. the minimum level of excess capacity that a firm requires to handle customer turnover, unexpected outages, or internal maintenance procedures. If the firm requires a certain level of administrative fill, then it would invest in new capacity when this minimum level of excess capacity was reached.
} 
anticipation of future demand growth. Thus, the second incentive is to accelerate the rate at which capacity is acquired before it is ultimately used. The strength of this second incentive depends on the extent of increasing returns. If capacity acquisition has constant returns then the second incentive disappears and efficient new investments are made only to accommodate current new demand or replacement of currently obsolete capacity.

To establish benchmarks, we assume capacity at time $t=0$ is at the lowest possible level, so new investment is required at time $t=0$ in order to satisfy demand in the immediate future. In the expected innovation date scenario this means capacity is $Q(0)$ at time $t=0$. In the light bulb scenario this means capacity is zero at time $t=0$. The latter is sometimes known as a "green field" approach, and is close to the approach taken in most TELRIC cost studies. ${ }^{30}$ However, we also investigate efficient investment plans that begin with excess capacity. The results which assume initial excess capacity (in both scenarios) indicate how an efficient plan changes when an incumbent's existing plant is taken into account. This alternative approach is closer in spirit to traditional incremental costing methodologies that have long been used in regulatory analysis.

\subsection{Expected innovation date replacement}

In this scenario, there is a future expected innovation date $D>0$ at which all assets acquired before that date become obsolete. At date $D$ all past decisions about the particular asset type under study become irrelevant to the firm's subsequent investment decisions. ${ }^{31}$ Hence the cost minimization problem starting at time $t=0$ has a finite time horizon that lasts only until time $t=D$. Since increasing returns implies that optimal investment occurs in discrete amounts, the cost minimizing investment plan will involve a finite number $n$ of investment times.

The firm begins at time $t=0$ with an initial capacity $I_{0} \geq Q(0)$ that was acquired at some time prior to $t=0$. Since all assets installed before date $D$ remain productive until date $D$, the productive capacity at any time $t$ in the relevant time horizon is $\sum_{j=0, T_{j}<t}^{n} I_{j}$. Moreover, since it is cost-minimizing to delay investments until all existing capacity is in use, the efficient investment undertaken at time $T_{k}$ will be to install exactly enough capacity to satisfy demand growth through the next investment time $T_{k+1}$. That is,

$I_{k}=Q\left(T_{k+1}\right)-\sum_{j=0}^{k-1} I_{j}$, for $k=1, \ldots, n$,

where $T_{n+1}$ is defined to be $D$ (i.e., the last investment must install exactly enough capacity to satisfy demand growth through the end of the relevant time horizon), and the first investment time is determined by $I_{0}=Q\left(T_{1}\right)$. Therefore $I_{k}=Q\left(T_{k+1}\right)-Q\left(T_{k}\right)$ for $k=1$,

\footnotetext{
${ }^{30}$ However, many cost proxy models assume some additional constraints on feasible investment plans. For example, the Synthesis Model assumes that loop and switching facilities are designed based on the location of existing wire centers.

${ }^{31}$ This description is admittedly a caricature. However, the majority of certain types of assets are indeed replaced within very short time periods relative to the length of time the assets are used. We believe the fixed (expected) innovation date scenario is a useful conceptual and modeling tool even though, like all models, it is stylized compared with the real world.
} 
$\ldots, n .^{32}$ This expression is a demand constraint on the cost-minimizing relationship between investment capacities and investment times.

For a fixed number of investment times $n$, the cost minimization problem is to choose the investment times and capacities at each time to minimize the present value of the investment cost, $\sum_{k=1}^{n} e^{-r T_{k}} F\left(I_{k}, T_{k}\right)$, subject to the demand constraint. Using the demand constraint and the assumed functional forms for investment cost and demand, the cost minimization problem is

$$
\begin{aligned}
& \operatorname{Min} \sum_{k=1}^{n} e^{(\lambda-r) T_{k}} f\left(Q(0)\left[e^{\eta T_{k+1}}-e^{\eta T_{k}}\right]\right) \\
& \left\{T_{2}, \ldots, T_{n}\right\}
\end{aligned}
$$

where $T_{1}=\frac{\ln \left(I_{0}\right)-\ln (Q(0))}{\eta}$ and $T_{n+1}=D$.

Once equation (8) is parameterized with input values, the cost-minimizing investment plan can be found as a numeric solution to (8) for a given $n$, nested within a numeric search over $n$. Since the scenario under consideration is replacement at an "expected innovation date", which is representative of switching assets, we parameterize (8) with input data on the cost of switching equipment that was developed for the Synthesis Model during the FCC's universal service proceedings. These inputs are based on regression analysis of switching contracts supplied to the FCC during that proceeding, which were used to estimate the initial investment cost function for autonomous end-office digital switches $f(I)=486,000+87 I$, where $I$ is the number of lines on the switch. ${ }^{33}$ As in section 2.5 , our benchmark analysis assumes that this cost decreases at an annual rate of $-10.98 \%$ per year, implying a continuous rate of $\lambda=-0.1163$, and the innovation date is $D=16$. To establish a benchmark, we further assume that demand grows at the continuous rate $\eta$ $=0.02$ (approximately $2 \%$ per year), initial demand is $Q(0)=20,000$ lines, and there is no initial excess capacity (i.e., $I_{0}=Q(0)$, so $T_{1}=0$ ).

The benchmark efficient investment plan is shown in Figure 15. It involves an initial investment in switching of 3,365 lines at a cost of $\$ 778,728$, followed by one subsequent investment after 7.8 years of 4,178 lines at cost $\$ 343,925$. The minimized present value of cost is $\$ 928,878$. The percentage of excess capacity in the efficient investment plan is shown in Figure 16. The initial investment installs excess capacity of 3,365/23,365 = $14.4 \%$, which is gradually used by growing demand until reaching zero at the time of the second investment. The second investment then installs excess capacity of $4,178 / 27,543=15.2 \%$. The average utilization rate ( 1 - average excess capacity) is $91.5 \%$.

\footnotetext{
${ }^{32}$ We note that by assumption demand growth is monotonically increasing, so that this expression is well defined.

${ }^{33}$ Strictly speaking, this cost function may not be an appropriate cost function for the current analysis since it estimates the full stand alone cost of a fully configured switch, and not the cost of additional line cards and other growth additions. In the absence of alternative public data on switching costs, we use it for illustrative purposes only. In addition, we have not attempted to verify that it is an accurate representation of current switching costs.
} 


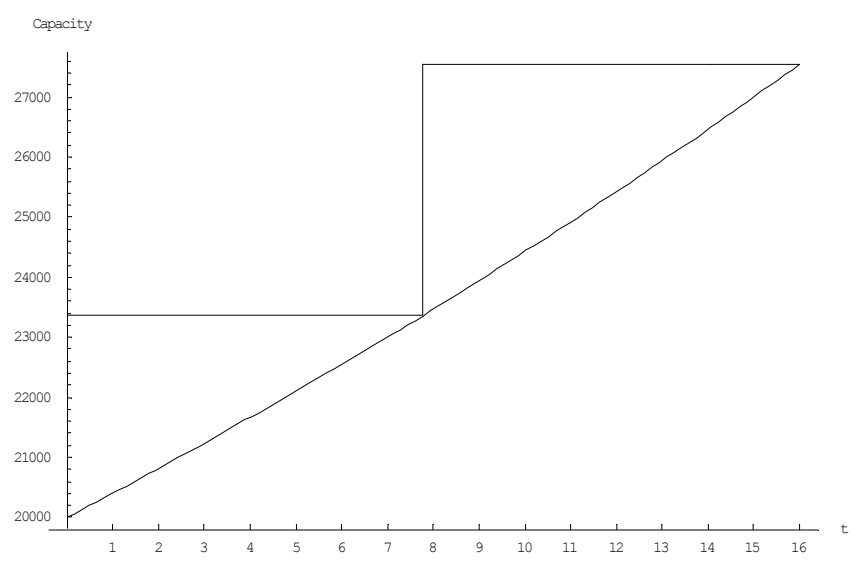

Figure 15: Demand and efficient capacity, benchmark case switching scenario

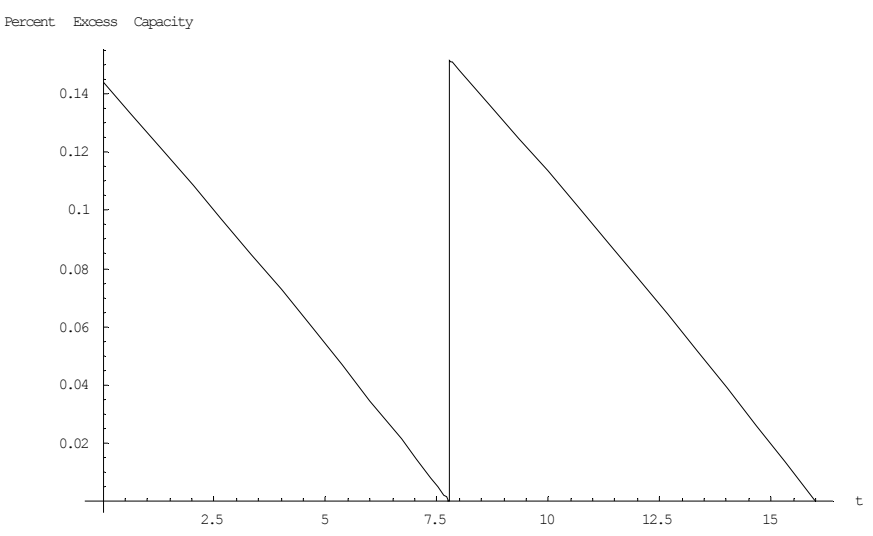

Figure 16: Percent excess capacity, benchmark case switching scenario

Table 1 summarizes the results for various parameterizations. The benchmark parameterization is in row 1. Subsequent rows report only those parameters that differ from the benchmark. The second row, which may be interpreted as an incremental cost calculation, shows the optimal investment plan if initial demand is only $80 \%$ of initial capacity. This initial excess capacity is adequate to satisfy demand until year 11.2, at which time efficient investment installs exactly enough capacity to satisfy demand through the end of the horizon. Costs are much lower than in the benchmark plan, because the initial excess capacity both reduces the need for new investment and forestalls the time of that investment. The third row examines the effect of a change in the cost of capital. It shows that the optimal plan places heavier emphasis on delaying investment costs rather than exploiting scale economies when the cost of capital is higher. This delaying tactic, along with the pure discounting effects of a lower discount factor, reduces the present value of the plan compared with the benchmark even though the total cash outlay is higher. The fourth row shows how a $50 \%$ delay in the innovation date affects the optimal investment plan. The second investment is accelerated slightly and a large third investment is added. The total cost in current dollars does not increase much because the large third investment is discounted over 15 years and reflects 15 years of falling investment costs. Finally, the last row shows the effect of a slower decline in equipment prices. Investment is 
delayed relative to the benchmark because later costs are relatively higher, and total cost increases.

\begin{tabular}{|c|c|c|c|c|}
\hline \multirow{2}{*}{ Parameters } & \multicolumn{3}{|c|}{ Efficient investment plan } & \multirow{2}{*}{$\begin{array}{c}\text { Present value } \\
\text { of } \\
\text { minimum } \\
\text { cost }\end{array}$} \\
\hline & Times & Amounts & Costs & \\
\hline $\begin{array}{c}\text { Benchmark } \\
r=10.66 \% \\
\lambda=-11.63 \% \\
D=16 \\
\eta=2 \% \\
Q(0)=20,000 \\
I_{0}=20,000\end{array}$ & $\begin{array}{c}T_{1}=0 \\
T_{2}=7.8\end{array}$ & $\begin{array}{l}I_{1}=3,365 \\
I_{2}=4,178\end{array}$ & $\begin{array}{c}F\left(I_{1}, T_{1}\right)= \\
\$ 778,728 \\
F\left(I_{2}, T_{2}\right)= \\
\$ 343,925\end{array}$ & $\$ 928,878$ \\
\hline$Q(0)=16,000$ & $T_{1}=11.2$ & $I_{1}=2,034$ & $\begin{array}{l}F\left(I_{1}, T_{1}\right)= \\
\$ 181,116\end{array}$ & $\$ 55,135$ \\
\hline$r=15 \%$ & $\begin{array}{c}T_{1}=0 \\
T_{2}=6.7 \\
T_{3}=12.6\end{array}$ & $\begin{array}{l}I_{1}=2,859 \\
I_{2}=2,870 \\
I_{3}=1,813\end{array}$ & $\begin{array}{c}F\left(I_{1}, T_{1}\right)= \\
\$ 734,763 \\
F\left(I_{2}, T_{2}\right)= \\
\$ 338,236 \\
F\left(I_{3}, T_{3}\right)= \\
\$ 148,795\end{array}$ & $\$ 881,415$ \\
\hline$D=24$ & $\begin{array}{c}T_{1}=0 \\
T_{2}=7.6 \\
T_{3}=15.2\end{array}$ & $\begin{array}{l}I_{1}=3,305 \\
I_{2}=3,821 \\
I_{3}=5,196\end{array}$ & $\begin{array}{c}F\left(I_{1}, T_{1}\right)= \\
\$ 773,538 \\
F\left(I_{2}, T_{2}\right)= \\
\$ 336,304 \\
F\left(I_{3}, T_{3}\right)= \\
\$ 159,442\end{array}$ & $\$ 953,794$ \\
\hline$\lambda=-5 \%$ & $\begin{array}{c}T_{1}=0 \\
T_{2}=8.9\end{array}$ & $\begin{array}{l}I_{1}=3,894 \\
I_{2}=3,645\end{array}$ & $\begin{array}{c}F\left(I_{1}, T_{1}\right)= \\
\$ 824,759 \\
F\left(I_{2}, T_{2}\right)= \\
\$ 515,010\end{array}$ & $\$ 1,024,310$ \\
\hline
\end{tabular}

Table 1: Efficient investment plans in scenario 1 (switching)

The results in Table 1 cannot be directly utilized as inputs to the TELRIC pricing rules discussed in section 2 because the replacement regime in section 2 was the "fixed life" 
scenario (i.e. assets last exactly $L$ years) rather than the "expected innovation date" scenario in Table 1 (where assets are retired on a given date $D$ regardless of age). Alternative TELRIC rules, as yet unexplored in the literature, are needed for assets whose obsolescence is best described by the expected innovation story. In the next two sections we explore how efficient investment plans that are derived for the "fixed life" scenario can be directly used in TELRIC pricing rules.

\subsection{Light bulb replacement}

In this scenario, there is a fixed useful life $L>0$ for each asset. Since there is no date at which the regime is expected to end, the cost minimization problem starting at time $t=0$ has an infinite time horizon.

The firm begins at time $t=0$ with initial capacity that was acquired at some time(s) prior to $t=0$. This initial capacity may consist of different vintages. For notational convenience, denote those capacities, in order of age, by $I_{-(b-1)}, I_{-(b-2)}, \ldots, I_{0}$ and their installation times by $T_{-(b-1)}, T_{-(b-2)}, \ldots, T_{0}$, where $b \geq 1$ is the number past investments that are still productive at time $t=0$ (if there are no productive investments left at time $t=0$ then we set $b=1, T_{0}=0$, and $I_{0}=0$ ). The productive capacity at any time $t \geq 0$ is the sum of those capacities that are not older than $L$. So the existing productive capacity at an investment time $T_{k} \geq 0$ is $\sum_{j=-(b-1)}^{k-1} \chi\left(T_{k} \leq T_{j}+L\right) I_{j}$, where $\chi(C)=1$ if condition $C$ is true and 0 otherwise.

As in the "expected innovation date" replacement scenario, it is cost-minimizing to delay investments until all existing capacity is in use, so the efficient investment undertaken at time $T_{k}$ must install exactly enough capacity to satisfy demand growth through the next investment time $T_{k+1}$. That is,

$$
I_{k}=Q\left(T_{k+1}\right)-\sum_{j=-(b-1)}^{k-1} \chi\left(T_{k+1} \leq T_{j}+L\right) I_{j}, \text { for } k=1,2, \ldots,
$$

where the first investment time is the smallest value of $T_{1}$ such that $Q\left(T_{1}\right) \geq \sum_{j=-(b-1)}^{0} \chi\left(T_{1} \leq T_{j}+L\right) I_{j}$. These expressions are the demand constraints on the cost-minimizing relationship between investment capacities and investment times.

The cost minimization problem is to choose the investment times and capacities at each time to minimize the present value of the investment cost,

$$
\sum_{j=1}^{\infty} e^{-r T_{j}} F\left(I_{j}, T_{j}\right)=\sum_{j=1}^{\infty} e^{(\lambda-r) T_{j}} f\left(I_{j}\right)
$$

subject to the demand constraints. In general, this is an infinite horizon optimization problem that is non-recursive, and therefore it cannot be solved with standard techniques such as those discussed in Stokey and Lucas (1989). In the examples below, we solve it for finite planning horizons where the times of investment are restricted to integer values. ${ }^{34}$

\footnotetext{
${ }^{34}$ Subject to these restrictions, the algorithm we use searches for a global cost minimum of investment times for any given number of investments, nested within a search over the number of investments. There is no guarantee that the resulting solution is a global cost minimum, although the solutions we find are below the theoretical upper bound described in section 3.4. A numerical solution to this problem has been implemented in Mathematica.
} 
This "light bulb" replacement scenario is representative of loops, so we parameterize it with publicly available data ${ }^{35}$ on loop costs from the state of Maryland. With these data, a run of the Synthesis Model was completed in which inputs representing utilization factors were set equal to $100 \% .{ }^{36}$ Disaggregated loop investment costs, representing distribution facilities, feeder facilities, and loop electronics were then extracted from the model outputs for each of the 189 wire centers in the state. A set of loop cost functions were derived from regressions of investment costs on the number of access lines and wire center area. For distribution investments, the results are as follows.

\begin{tabular}{|c|c|c|c|c|c|}
\hline Parameter & & Estimate & $\mathrm{SE}$ & TStat & PValue \\
\hline Constant & & 55974.3 & 218400 & 0.256292 & 0.798013 \\
\hline Lines & & 276.35 & 7.95594 & 34.735 & 0 \\
\hline Lines $^{2}$ & & -0.00112738 & 0.0000614206 & -18.3551 & $2.3445910^{-43}$ \\
\hline Area & & 49270.6 & 4745.78 & 10.382 & 0 \\
\hline Area $^{2}$ & & -77.0684 & 23.8266 & -3.23455 & 0.0014457 \\
\hline $\begin{array}{l}\text { Area } \\
\text { lines }\end{array}$ & $*$ & 0.717975 & 0.0796032 & 9.01942 & $2.2204510^{-16}$ \\
\hline
\end{tabular}

By varying both the number of lines and wire center area, it is possible to represent loop investment cost under different conditions of scale and density. Using an area equal to the mean area of the Maryland sample data (52 square miles) resulted in a distribution cost function

$$
f(I)=2.4 * 10^{6}+314 I-0.001 I^{2}
$$

where investment $I$ represents the number of access lines. This cost function implies that average cost is steeply declining over the range of reasonable outputs as illustrated in Figure 17 below. Average investment cost functions for feeder and electronics exhibit similar, though less pronounced, scale economies, as also illustrated in Figure 17.

\footnotetext{
${ }^{35}$ The Maryland data used in this simulation are based on customer locations created by randomly distributing the population of each Census block within the block boundaries. These data are available on the internet at http://www.fcc.gov/wcb/tapd/hcpm/ and while they are less accurate than those actually used in the Synthesis Model, they are capable of capturing the economies of density and scale that characterize loop investment costs over a large and diverse geographic area.

${ }^{36}$ Therefore, the resulting cost function $f(I)$ represents the cost of deploying exactly $I$ loops instead of the cost of deploying loop plant to satisfy a current demand for $Q<I$ loops, as in the standard operation of the Synthesis Model.
} 


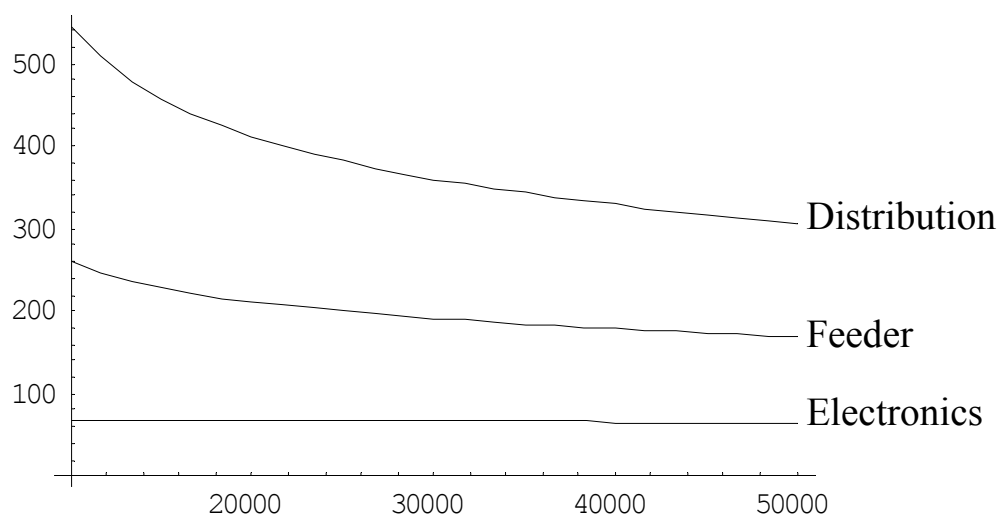

Figure 17: Average cost of distribution, feeder and electronics investment estimated for Maryland

As in section 2.6, our benchmark analysis assumes that cost increases at a continuous rate of $\lambda=.03$ (approximately 3\% per year) and that the useful life is $L=30$. As in the previous section, we assume that demand grows at the continuous rate $\eta=0.02$. Moreover, to establish a benchmark, we assume a planning horizon equal to twice the asset life (60 years), initial loop demand equal to $Q(0)=10,000$ lines, and no initial capacity (i.e., all units of initial capacity are assumed to expire at time $t=0$ ). For the benchmark case, the cost minimizing capacity path is illustrated in Figure 18 and the implied levels of excess capacity are shown in Figure 19. The average utilization rate associated with this capacity expansion sequence is $86.7 \%$.

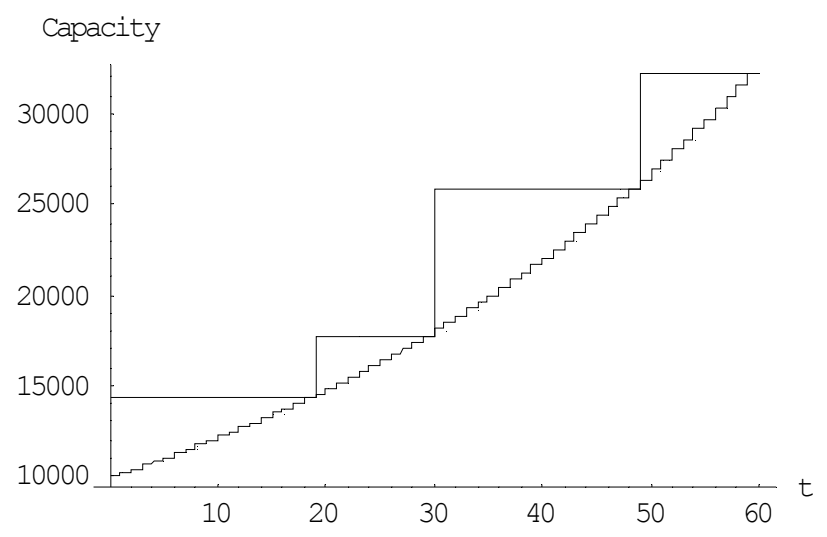

Figure 18: Demand and efficient capacity, benchmark case loop scenario 


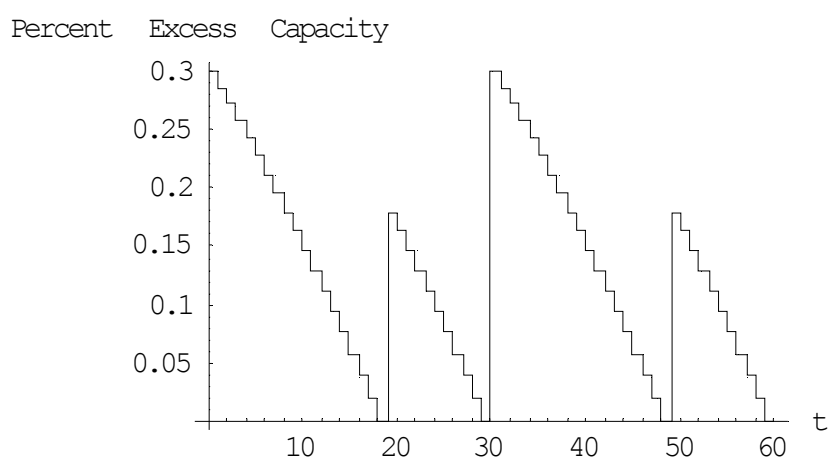

Figure 19: Percent excess capacity, benchmark case loop scenario

Table 2 presents results when some of the benchmark assumptions are modified. ${ }^{37}$ As the cost of capital rises, it becomes more expensive to have units of unused capacity and the present value of future investment costs is reduced. As a result, there is a reduction in the size of the initial investment and a corresponding acceleration in the time that subsequent investments are made. When investment costs are assumed constant, instead of increasing at the benchmark rate of $3 \%$ per year, the size of the initial investment is again reduced modestly. If the life of the asset is 15 years, substantially less than in the benchmark case, it is efficient to invest as infrequently as possible under the light bulb replacement scenario. The cost minimizing investment plan then consists of investments made at 15 year intervals with no intermediate investments.

If there is existing capacity from previous investments at time $t=0$, then the time of initial investment is delayed until demand growth exhausts the initial capacity. In this situation, the cost minimizing investment plan of an efficient firm should take account of these initial investments. However, the timing of subsequent investment decisions will not, in general, have a simple relationship to the time that existing investments were made. ${ }^{38}$ The last row of Table 2 and Figure 20 describe the efficient investment program for one possible set of initial conditions.

\footnotetext{
${ }^{37}$ In this table only we use the notation $F^{j}=F\left(I_{j}, T_{j}\right)$.

${ }^{38}$ Note that the optimal investment plan illustrated in Figure 20 has existing assets retired at times $t=10,15$, 25 , and even as late as year 55, without any corresponding new investments at those times. Thus, initial capacities can have a substantial impact on the firm's capital stock even after many years have elapsed.
} 


\begin{tabular}{|c|c|c|c|c|}
\hline \multirow{2}{*}{ Parameters } & \multicolumn{3}{|c|}{ Efficient investment plan } & \multirow{2}{*}{$\begin{array}{l}\text { Present value } \\
\text { of } \\
\text { minimum cost }\end{array}$} \\
\hline & Times & Amounts & Costs & \\
\hline $\begin{array}{c}\text { Benchmark } \\
r=11.25 \% \\
\lambda=3 \% \\
L=30 \\
\eta=2 \% \\
Q(0)=10,000 \\
I_{0}=0 \\
T_{0}=0\end{array}$ & $\begin{array}{l}T_{1}=0 \\
T_{2}=19 \\
T_{3}=30 \\
T_{4}=49\end{array}$ & $\begin{array}{l}I_{1}=14,283 \\
I_{2}=3,476 \\
I_{3}=22,395 \\
I_{4}=9,772\end{array}$ & $\begin{array}{c}F^{1}=\$ 6,659,870 \\
F^{2}=\$ 6,113,410 \\
F^{3}=\$ 21,527,700 \\
F^{4}=\$ 22,844,800\end{array}$ & $\$ 8,468,400$ \\
\hline$r=15 \%$ & $\begin{array}{l}T_{1}=0 \\
T_{2}=17 \\
T_{3}=30 \\
T_{4}=46\end{array}$ & $\begin{array}{l}I_{1}=13,728 \\
I_{2}=4,031 \\
I_{3}=20,348 \\
I_{4}=11,819\end{array}$ & $\begin{aligned} F^{I} & =\$ 6,503,410 \\
F^{2} & =\$ 6,042,270 \\
F^{3} & =\$ 20,208,700 \\
F^{4} & =\$ 23,213,000\end{aligned}$ & $\$ 7,407,570$ \\
\hline$\lambda=0$ & $\begin{array}{l}T_{1}=0 \\
T_{2}=17 \\
T_{3}=30 \\
T_{4}=47\end{array}$ & $\begin{array}{l}I_{1}=13,728 \\
I_{2}=4,031 \\
I_{3}=20,836 \\
I_{4}=11,331\end{array}$ & $\begin{array}{l}F^{l}=\$ 6,503,410 \\
F^{2}=\$ 3,655,670 \\
F^{3}=\$ 8,456,020 \\
F^{4}=\$ 5,819,390\end{array}$ & $\$ 7,484,330$ \\
\hline$L=15$ & $\begin{array}{l}T_{1}=0 \\
T_{2}=15 \\
T_{3}=30 \\
T_{4}=45\end{array}$ & $\begin{array}{l}I_{1}=13,195 \\
I_{2}=17,758 \\
I_{3}=23,901 \\
I_{4}=32,167\end{array}$ & $\begin{aligned} F^{I} & =\$ 6,352,370 \\
F^{2} & =\$ 11,879,000 \\
F^{3} & =\$ 22,483,400 \\
F^{4} & =\$ 42,858,400\end{aligned}$ & $\$ 10,024,400$ \\
\hline $\begin{array}{c}I_{0}=2,000 \\
I_{-1}=3,000 \\
I_{-2}=6,000 \\
T_{0}=-5 \\
T_{-1}=-15 \\
T_{-2}=-20\end{array}$ & $\begin{array}{l}T_{1}=5 \\
T_{2}=24 \\
T_{3}=35 \\
T_{4}=53\end{array}$ & $\begin{array}{l}I_{1}=13,769 \\
I_{2}=5,838 \\
I_{3}=22,166 \\
I_{4}=10,002\end{array}$ & $\begin{aligned} F^{I} & =\$ 7,552,710 \\
F^{2} & =\$ 8,542,720 \\
F^{3} & =\$ 24,786,600 \\
F^{4} & =\$ 26,032,000\end{aligned}$ & $\$ 5,778,770$ \\
\hline
\end{tabular}

Table 2: Efficient investment plans in scenario 2 (loops) 


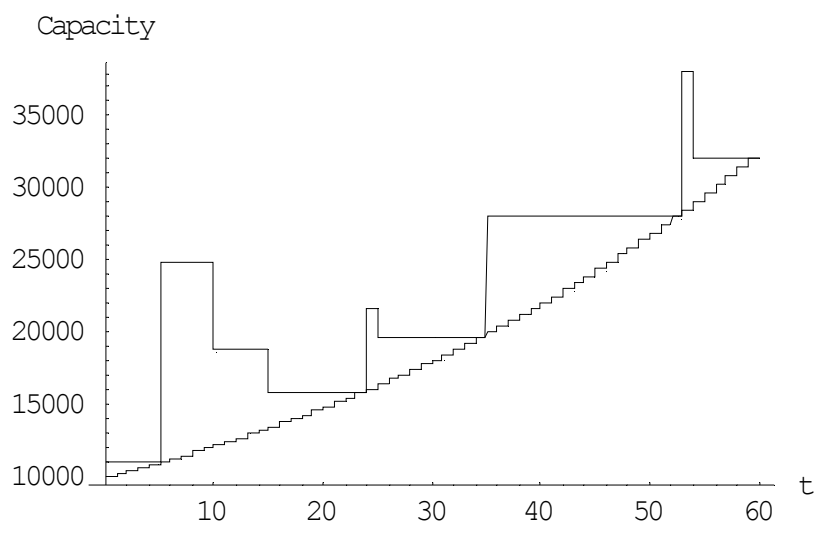

Figure 20: Demand and efficient capacity, loop scenario with initial installed capacity at time $t=0$

\subsection{Implications for TELRIC pricing}

Let us now consider some implications of the "light bulb" efficient investment results for TELRIC pricing. TELRIC pricing rules have traditionally been defined in an environment in which little or no account is taken of market dynamics. In particular, current TELRIC pricing rules are generally defined without reference to either expected changes in future investment cost or expected changes in future demand (or utilization rates). In section 2.7 we illustrated how a simple multiplicative correction factor could be defined to take proper account of changing investment cost. Under corrected TELRIC pricing, a regulated firm would exactly recover its forward looking investment cost, even if TELRIC price reviews occur at intervals shorter than assumed asset lifetimes. In section 2.8 , it was similarly demonstrated that varying utilization rates, which could result from cost minimizing decisions made in the face of growing demand, could be easily incorporated into the TELRIC pricing rule.

Sections 3.2 and 3.3 have focused on another aspect of efficient investment planning in a dynamic environment. In these sections, a cost minimizing investment program was explicitly calculated in a variety of circumstances. In order to complete our analysis, it only remains to demonstrate how these cost minimizing investment decisions can be used as inputs into a fully efficient forward looking pricing regime. In the case of assets having light bulb performance characteristics this process is relatively straightforward. The TELRIC prices for a sequence of investments made as part of an optimal investment plan now depend on the demand conditions at the time at which the investment occurs. ${ }^{39}$ With this modification, equation (5) of section 2 is repeated using notation of the current section as equation (10): ${ }^{40}$

\footnotetext{
${ }^{39}$ In section 2, utilization rates, which play the same role as aggregate demand in section 3, were generally assumed to be constant. In the case of growing utilization rates discussed in section 2.8 , the utilization rate path was assumed to be based on the time of investment rather than calendar time.

${ }^{40}$ Analogous to equation (5), equation (10) only prices the investment made at time $T_{k}$ and, in particular, is not pricing any other assets that may be in service simultaneously with the asset placed in service at time $T_{k}$. If there are multiple assets in service at a particular time then the total price charged at that time according to (10) will be the sum of the prices defined in (10) over all assets in service. Equation (10) is certainly not the
} 


$$
\text { pTelric }_{T_{k}}=\frac{F\left(I_{k}, T_{k}\right)}{\sum_{j=0}^{L-1} \delta^{j} Q\left(T_{k}+j\right)}
$$

where $F$ is the investment cost function; $I_{1}, \ldots, I_{\mathrm{n}}$ is a sequence of cost minimizing investments; $T_{1}, \ldots, T_{n}$ is a sequence of investment times; and $Q($.$) is aggregate demand.$

In contrast, TELRIC prices as actually calculated in practice are usually based on a somewhat different set of assumptions. Actual TELRIC prices assume that a single investment is made at the time of a costing study. The size of the initial investment is determined by current demand divided by an exogenously determined utilization rate. In the current notation of section 3, where $q$ is an assumed utilization rate and $T$ is the time of the TELRIC study, these prices are defined in equation (11):

$$
\text { pActualTelric }_{T}=\frac{F(Q(T) / q, T)}{Q(T) \sum_{j=0}^{L-1} \delta^{j}}
$$

In section 2.7 we derived a contestable price path and argued that TELRIC prices ought to emulate these prices when the regulated firm faces potential competition from rival carriers. Like the TELRIC prices considered in section 2.7, the contestable prices assumed an investment in a single asset and a utilization path that is invariant to the time of investment. Also like the TELRIC prices in (10), the contestable price definition now depends on demand conditions at the time at which the investment occurs. Moreover, unlike TELRIC prices, which are designed to recover only the cost of an asset installed at the time of a TELRIC cost study, contestable prices must make efficient entry yield zero economic profit over the entire future of the entrant, at every potential entry time. Hence the contestable price path in now defined by

$$
\sum_{t=T}^{T+H} \delta^{t-T} p \text { Contestable }_{t} Q(t)=P V(T) \text { for } T=0,1, \ldots
$$

where $P V(T)=\sum_{k=1}^{n} \delta^{T_{k}(T)-T} F\left(I_{k}(T), T_{k}(T)\right)$ is the present value cost of a sequence of cost minimizing investments $I_{1}(T), \ldots, I_{n}(T)$ made at times $T_{1}(T), \ldots, T_{n}(T)$ for a de novo entrant at time $T=T_{1}(T)$, and $H$ is the planning horizon used to calculate the cost minimum.

Solving equation (12) for the contestable price path gives

$$
\text { pContestable }_{T}=\frac{P V(T)-\delta P V(T+1)}{Q(T)}+R(T) \text { for } T=0,1, \ldots, H-1,
$$

where

only way to price multiple assets. Other rules, which involve a different method of cost allocation over time, can easily be constructed. In any case, we do not at this point consider use of equation (10), or any of its possible variants, to be particularly useful as practical pricing rules. 


$$
R(T)=\frac{\delta^{H} p \text { Contestable }_{T+H} Q(T+H)}{Q(T)}
$$

is a remainder that arises because the finite horizon $H$ is used to estimate the cost minimum while the actual costing and pricing problem has an infinite horizon. This remainder must be estimated in order to calculate (13), which means we must have an estimate of p Contestable C $_{T+H}$. As the planning horizon $\mathrm{H}$ becomes very long the remainder approaches zero, so one estimate is to simply ignore the remainder in calculating (13). Alternatively, under our stated assumptions it can be shown that

$$
p \text { Contestable }_{T} \leq \frac{(1-\delta \gamma) F(Q(T+L), T)}{\left(1-(\delta \gamma(1+\eta))^{L}\right) Q(T)} \text { for } T=0,1, \ldots
$$

which provides an upper bound on the contestable price path that can be used in (14) to place an upper bound on the remainder. ${ }^{41}$

Figure 21 compares the price paths (11) and (13) for the Benchmark case reported in Table 2 (with investment costs rising at 3\% per year), and Figure 22 shows these price paths under the same assumptions except that investment costs decline at the rate of 5\% per year. The actual TELRIC path (11) is assumed to be subject to TELRIC price reviews every three years ( $T$ increments by 3 ), and the assumed utilization rate is the expected utilization rate in the efficient investment plan. The contestable price path assumes that price reviews (by potential entrants) are conducted annually during every year of the 60 year planning horizon and ignores the remainder. ${ }^{42}$

As was the case in section 2, TELRIC prices are less than contestable prices when investment costs are falling and greater than contestable prices when investment costs are rising. ${ }^{43}$ Also as in section 2, the dynamic pattern of both TELRIC prices and contestable prices follows the dynamic pattern of investment costs, and the TELRIC prices could be corrected to yield the same rate of return as the contestable prices. If investment costs do not change over time (i.e. $\lambda=0$ ) then both TELRIC and contestable prices fall over time due to growing demand and economies of scale in the investment cost function.

\footnotetext{
${ }^{41}$ The upper bound in (15) is based on a simple feasible and recursive investment plan in which the firm invests once every $L$ periods, investing enough at each investment date to satisfy demand until the newly acquired assets expire. An investment plan based on these assumptions is representative of traditional network planning by ILEC engineers. See, for example, "Telcordia Notes on the Networks," p. 12-2, which states: "This (distribution) plant is designed to meet the greatest expected customer demand in an area for the life of the plant." Equation (15) also assumes non-decreasing returns in capacity acquisition over the range of acquired capacities, and that $0 \leq \delta \gamma(1+\eta)<1$, which holds in all of our examples.

${ }^{42}$ Only the first 30 years are illustrated. The monthly remainder is inconsequential, as an estimate based on the upper bound (15) does not exceed 23 cents per month during the 30 illustrated years in Figure 21 . When investment costs fall by $5 \%$ per year, as in Figure 22, the remainder term never exceeds 0.16 cents per month.

${ }^{43}$ TELRIC prices also understate contestable prices when investment costs are constant. The magnitude of the assumed utilization rate, or fill factor, also influences the relative magnitude of the two price schedules.
} 


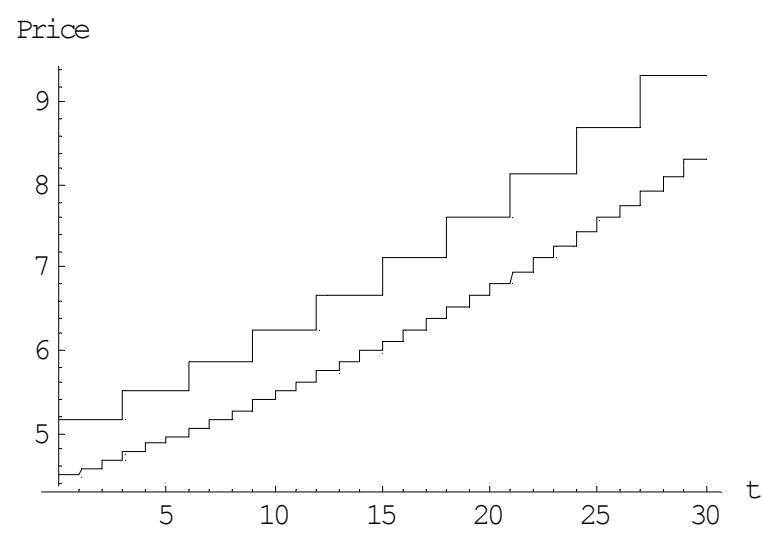

Figure 21: Monthly contestable and triennially reviewed actual TELRIC prices, distribution portion of loops: case of increasing investment cost

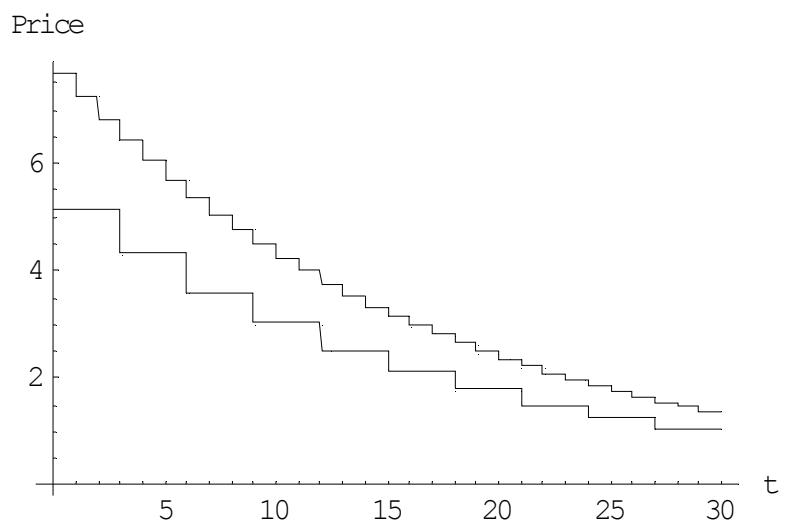

Figure 22: Monthly contestable and triennially reviewed actual TELRIC prices, distribution portion of loops: case of decreasing investment cost

The upper bound on prices given in (15) can be used to verify that the numerical dynamic cost minimum discussed in this section indeed gives important information about prices that is missed by a more crude estimate of costs. Figure 23 plots the upper bound (15) for the benchmark loop scenario along with the contestable price path from Figure 21. We see that the contestable prices based on dynamic cost minimization are substantially below the theoretical upper bound. As the theoretical upper bound is representative of traditional ILEC network planning (see footnote 41), Figure 23 shows that explicit consideration of dynamically efficient costs can result in substantially lower cost estimates than those based on traditional network planning. 


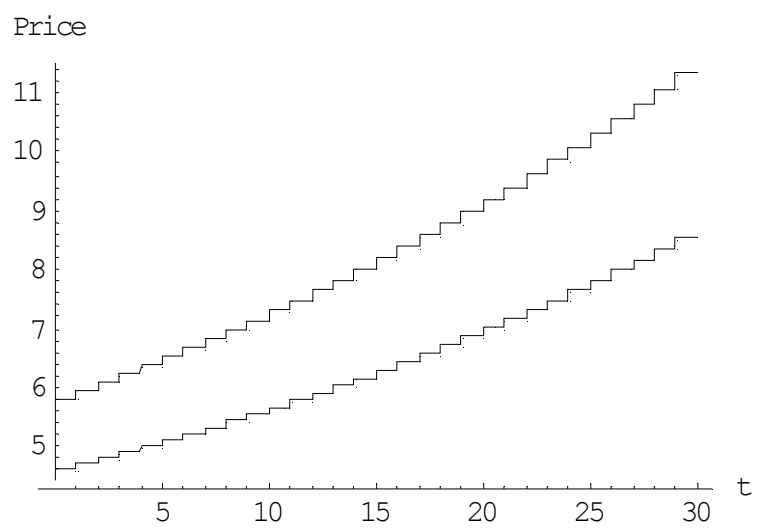

Figure 23: Monthly minimum cost contestable $\&$ theoretical upper bound prices, distribution portion of loops: case of increasing investment cost

Finally, we note that the results of this section suggest that alternative definitions of TELRIC pricing may be possible. Such definitions could capture some of the dynamic investment behavior considered herein. For example, the contestable price (13) could be used as a definition of a "dynamic" TELRIC price. These prices do not depend on embedded costs, so they are entirely forward-looking, but do have the feature that they are dynamically consistent: A firm that invests efficiently from time zero forward, and serves the whole demand included in the price calculation either directly or through unbundled elements, will exactly recover costs incurred at or after time zero with these prices, including the rate of return used in calculating the prices. Such prices can therefore be regarded as incentive regulation of investment decisions of entrant and incumbent firms. A price path calculated in this way would explicitly abandon levelization (even between TELRIC price reviews) and would be based on cost minimizing dynamic investment decisions at every point in time.

With these prices, a firm that has existing capacity at time zero will recover the cost of its existing capacity as well, provided:

(1) the existing capacity was obtained as part of a dynamically efficient investment plan,

(2) all current parameter estimates (including the expected rate of change of asset acquisition costs) are the same as they were when the existing capacity was installed, and

(3) past prices were calculated according to the contestable rule.

Some adjustment to the prices may be required if any of these properties do not hold. For example, the cost minima could be calculated with an estimate of existing capacity used as initial values, as in Figure 20, and then some addition could be made to the contestable prices to recover some costs associated with existing capacity at time zero. ${ }^{44}$ This would

\footnotetext{
${ }^{44}$ This approach would not necessarily require the use of historical depreciation. For example, the same cost function (or cost model) used to estimate future investment costs could be used with past parameter values to estimate the cost of efficient past investments. The resulting contestable price path could be compared to prices that actually prevailed to determine how much of efficiently incurred embedded costs have not yet been recovered and how much will be recovered during the remaining life of the assets.
} 
smooth the transition to fully forward-looking prices by providing a way to recover some embedded costs that were incurred under a previous regulatory compact. Details of possible additions for embedded costs, that preserve incentives for efficient entry and exit, are left for future research.

\section{$4 \quad$ Concluding comments}

The objective of this paper has been to evaluate the use of static cost proxy models in setting forward-looking prices such as the prices set according TELRIC. Section 2 compared the time paths of prices and depreciation under traditional regulatory accounting with the prices and depreciation implied by various versions of TELRIC. Under levelized TELRIC pricing, where prices are assumed to remain constant for the entire economic life of an asset, both prices and implied depreciation schedules follow significantly different trajectories than under traditional regulation. Under both pricing rules, however, the firm earns revenues that fully recover investment costs and a target rate of return.

When TELRIC prices are recomputed at intervals shorter than asset lives and investment costs change over time, however, the firm will generally not earn the target rate of return. In these cases, a correction factor must be applied to the TELRIC price path in order for revenues to exactly recover investment cost, including the target rate of return. When investment costs are falling by $11 \%$ per year (as is assumed for switching assets in the FCC Synthesis Model), the TELRIC correction factor is approximately $50 \%$. That is, switching prices should be increased by $50 \%$ from those suggested by Synthesis Model runs. When investment costs are rising at the rate of inflation, assumed to equal $3 \%$ per year, the TELRIC correction factor is $-20 \%$. In this case, TELRIC prices should be reduced by $20 \%$ from those suggested by model outputs.

Section 3 of the paper considered a firm's cost minimizing investment decisions over time. Two different assumptions about asset lives were analyzed. Under one scenario, characterized as "light bulb" performance, assets have a fixed and known physical life. In a second scenario the assets last forever, but due to technological change it is assumed that they will be replaced by a new generation of assets regardless of the date at which the original assets were put into service. In both scenarios the optimal investment path and the implied utilization rates were derived under a variety of assumptions about the relevant input parameters. TELRIC pricing rules, as well as a contestable pricing rule, were considered.

\section{$5 \quad$ References}

Alleman, J. (1999) "The Poverty of Cost Models, the Wealth of Real Options," Real Options: The New Investment Theory and its Implications for Telecommunications Economics, Boston: Kluwer Academic Publishers.

Biglaiser, G. and M. Riordan (2000) "Dynamics of Price Regulation," RAND Journal of Economics, 31: 744-67. 
Federal Communications Commission (1996) Implementation of the Local Competition Provisions of the Telecommunications Act of 1996, First Report and Order (Local Competition Order), CC Docket No. 96-988, 11 FCC Rcd 15499.

Federal Communications Commission (1999) Federal-State Joint Board on Universal Service, Forward-Looking Mechanism for High Cost Support for Non-Rural LECs, Tenth Report and Order, CC Docket Nos. 96-45, 97-160, FCC 99-304.

Hausman, J. A. (1997) "Valuing the Effect of Regulation on New Services in Telecommunications," Brookings Papers on Economic Activity (Microeconomics), 1-38.

Kahn, A. (2001) Whom the Gods would Destroy, or How Not to Deregulate, AEIBrookings Joint Center for Regulatory Studies.

Kahn, A. (1998) Letting Go: Deregulating the Process of Deregulation, East Lansing, MI: Institute of Public Utilities and Network Industries, Michigan State University.

Kahn, A., T. J. Tardiff, and D. L. Weisman (1999) "The 1996 Telecommunications Act at Three Years: An Economic Evaluation of its Implementation by the FCC," Information Economics and Policy, 11: 319-65.

Mandy, D. M. (2002) "TELRIC Pricing with Vintage Capital," Journal of Regulatory Economics, 22: 215-249.

Salinger, M. A. (1999) "Lowering Prices with Tougher Regulation: Forward-Looking Costs, Depreciation, and the Telecommunications Act of 1996," Regulation under Increasing Competition, Boston: Kluwer.

Salinger, M. (1998) "Regulating Prices to Equal Forward-Looking Costs: Cost-Based Prices or Price-Based Costs," Journal of Regulatory Economics, 14: 149-64.

Sidak, J. G. and D. F. Spulber (1998) Deregulatory Takings and the Regulatory Contract, Cambridge: Cambridge University Press.

Stokey, N. L. and R. E. Lucas (1989) Recursive Methods in Economic Dynamics, Cambridge: Harvard University Press.

Tardiff, T. J. (2002) "Pricing Unbundled Network Elements and the FCC's TELRIC Rule: Economic and Modeling Issues," Review of Network Economics, 1: 132-46.

Telecommunications Act of 1996, Pub. L. No. 104, 110 Stat. 56 (1996 Act), 47 U.S.C.

Telcordia Technologies (2000) "Telcordia Notes on the Networks," Special Report SR2275, Issue 4, October.

Weingarten, M. and B. Stuck (2003) "Why ILECs Won't Invest," Business Communications Review, 58: 54-58. 
Weisman, D. L. (2002) "Did the High Court Reach an Economic Low in Verizon v. FCC?" Review of Network Economics, 1: 90-105.

Weisman, D. L. (2000) “The (In)Efficiency of the 'Efficient Firm' Cost Standard," The Antitrust Bulletin, XLV: 195-211. 